\title{
The basic ingredients of the North Atlantic storm track. Part I: land-sea contrast and orography
}

Article

Published Version

Brayshaw, D. J., Hoskins, B. J. and Blackburn, M. (2009) The basic ingredients of the North Atlantic storm track. Part I: landsea contrast and orography. Journal of the Atmospheric Sciences, 66 (9). pp. 2539-2558. ISSN 1520-0469 doi: https://doi.org/10.1175/2009JAS3078.1 Available at https://centaur.reading.ac.uk/4336/

It is advisable to refer to the publisher's version if you intend to cite from the work. See Guidance on citing.

To link to this article DOI: http://dx.doi.org/10.1175/2009JAS3078.1

Publisher: American Meteorological Society

Publisher statement: (c) Copyright 2009 of the American Meteorological Society. The AMS Copyright Policy is available on the AMS web site at http://www.ametsoc.org

All outputs in CentAUR are protected by Intellectual Property Rights law, including copyright law. Copyright and IPR is retained by the creators or other copyright holders. Terms and conditions for use of this material are defined in the End User Agreement. 


\section{CentAUR}

Central Archive at the University of Reading

Reading's research outputs online 


\title{
The Basic Ingredients of the North Atlantic Storm Track. Part I: Land-Sea Contrast and Orography
}

\author{
DAVID JAMES BRAYSHAW \\ Walker Institute, Department of Meteorology, University of Reading, Reading, Berkshire, United Kingdom \\ BRIAN HOSKINS \\ Department of Meteorology, University of Reading, Reading, Berkshire, United Kingdom \\ MiCHAEL BLACKBURN \\ Walker Institute, Department of Meteorology, and National Centre for \\ Atmospheric Science, University of Reading, Reading, Berkshire, United Kingdom
}

(Manuscript received 22 January 2009, in final form 17 April 2009)

\begin{abstract}
Understanding and predicting changes in storm tracks over longer time scales is a challenging problem, particularly in the North Atlantic. This is due in part to the complex range of forcings (land-sea contrast, orography, sea surface temperatures, etc.) that combine to produce the structure of the storm track. The impact of land-sea contrast and midlatitude orography on the North Atlantic storm track is investigated through a hierarchy of GCM simulations using idealized and "semirealistic" boundary conditions in a highresolution version of the Hadley Centre atmosphere model (HadAM3). This framework captures the largescale essence of features such as the North and South American continents, Eurasia, and the Rocky Mountains, enabling the results to be applied more directly to realistic modeling situations than was possible with previous idealized studies. The physical processes by which the forcing mechanisms impact the large-scale flow and the midlatitude storm tracks are discussed. The characteristics of the North American continent are found to be very important in generating the structure of the North Atlantic storm track. In particular, the southwest-northeast tilt in the upper tropospheric jet produced by southward deflection of the westerly flow incident on the Rocky Mountains leads to enhanced storm development along an axis close to that of the continent's eastern coastline. The approximately triangular shape of North America also enables a cold pool of air to develop in the northeast, intensifying the surface temperature contrast across the eastern coastline, consistent with further enhancements of baroclinicity and storm growth along the same axis.
\end{abstract}

\section{Introduction}

Developing a good understanding of the mechanisms controlling the North Atlantic storm track is important for many reasons. First, the position and intensity of the track has a strong influence on the weather and climate of Europe, with storms being closely linked to extreme wind and precipitation events. Second, the storm track is intimately related to, and feeds back upon, the large-scale

Corresponding author address: D. J. Brayshaw, The Walker Institute for Climate Research, Department of Meteorology, Earley Gate, University of Reading, P.O. Box 243, Reading, Berkshire, RG6 6BB, United Kingdom.

E-mail: d.j.brayshaw@rdg.ac.uk flow patterns and the structure of the tropospheric jet. Subtle shifts in the track can therefore lead to profound impacts on the climate, both locally and throughout the hemisphere. To interpret and have confidence in simulated changes in the climate of the extratropics, it is important to have a good understanding of storm track mechanisms.

Storms tend to form in regions of strong baroclinicity, and "aquaplanet" experiments with zonally symmetric sea surface temperatures give the expected zonally symmetric storm track (e.g., Inatsu et al. 2003). Recent work by Nakamura et al. (2008) and Brayshaw et al. (2008) has further shown that the latitudinal position of the track is connected to the relative locations of the subtropical jet and the midlatitude sea surface temperature front and to the atmospheric baroclinicity associated with them. 
The marked zonal localization of the observed storm tracks into the ocean basins is controlled by a number of features on the planetary surface, including

- extratropical land-sea contrast,

- tropical surface anomalies (e.g., land-sea contrast),

- orography, and

- extratropical SST anomalies,

each of which has a range of different impacts upon the storm tracks. This present paper will discuss the first three of these features; the fourth feature (extratropical SST anomalies) and its interactions with the other three will be discussed in a subsequent paper based on the results presented by Brayshaw (2006).

Consider first extratropical land-sea contrast. Over continental areas, moisture availability is reduced, consistent with a weakening of precipitation and storm growth. Hoskins and Valdes (1990) argue that diabatic heating associated with the storm track is important for maintaining the baroclinicity upon which the storm track depends. In addition to this, atmospheric flow passing over continental areas experiences stronger surface drag than over the oceans, which acts to damp the surface wind anomalies associated with storms (Chang and Orlanski 1993) while restoring the near-surface baroclinicity required for storm growth (Robinson 1996). Furthermore, the land surface has a smaller heat capacity than the ocean and has no horizontal heat transport mechanism. In winter, therefore, there are stronger meridional surface temperature gradients over the continents (due to latitudinal differences in insolation) than over the oceans, and strong zonal temperature contrasts between the relatively warm extratropical oceans and the cold continental interiors. These surface temperature gradients can influence the baroclinicity of the atmosphere and hence the storm track (e.g., Walter et al. 2001; Inatsu et al. 2000; Frisius et al. 1998).

Land-sea contrast in the tropics can also have an impact on the midlatitude flow. Cook (2003) demonstrated that increases in the surface drag due to tropical continents were important in driving the Hadley circulation and, through this, the subtropical jet. Changes in surface heat capacity can also have a profound impact on the surface sensible and latent heat fluxes and consequently the diabatic heating higher in the tropical troposphere. Such responses have been studied through tropical SST anomaly experiments (e.g., Neale and Hoskins 2000b) and tropospheric heating anomalies (e.g., Gill 1980; Jin and Hoskins 1995), which are capable of radiating Rossby waves poleward and eastward into the midlatitudes (Sardeshmukh and Hoskins 1988; Hoskins and Karoly 1981), although the signal produced by changes in the properties of the tropical land surface can be quite weak, particularly in the lower troposphere (Brankovic et al. 2006; Zhang et al. 1996; Valdes and Hoskins 1989; Nigam et al. 1986).

The orography of the Northern Hemisphere has a profound effect on the westerly flow that dominates the midlatitudes. This flow can either be deflected vertically "over" or horizontally "around" the mountain such that if the perturbation in potential temperature associated with meridional deflection around the mountain is less than the corresponding vertical variation of potential temperature, then horizontal deflection of the flow dominates (Valdes and Hoskins 1991):

$$
L\left|\frac{\partial \theta}{\partial y}\right|<H \frac{\partial \theta}{\partial z}
$$

where $L$ and $H$ are the meridional and vertical scales of the mountain, and $\theta$ is a reference temperature distribution. For a given horizontal scale, there is a "critical height," which, if exceeded, implies a blocking of the zonal flow and a deflection around the mountain (e.g., Ringler and Cook 1997; Rodwell and Hoskins 1996). The response to orography has been studied in a range of models (by, e.g., Held et al. 2002; Ringler and Cook 1997; Cook and Held 1992; Chen and Trenberth 1988; Hoskins and Karoly 1981) and it has been shown that midlatitude orography acts as a strong source of Rossby waves that can propagate throughout the extratropics, affecting the flow in remote regions. Idealized GCM studies investigating the impact of this on the storm tracks often find that the orography tends to localize the storm track and jet on the downstream side of the mountains (Cash et al. 2005; Inatsu et al. 2002), introducing a slight southwest-northeast tilt to the track. Simulations investigating the effect of realistic orographic distributions have tended to show that the mountains act to localize the storm track into the ocean basins (Wilson et al. 2009; Broccoli and Manabe 1992; Manabe and Broccoli 1990). The large-scale flow patterns generated by orography were also shown to contribute significantly to the cooling of northeastern North America (by northwesterly flow) and the warming of western Europe (by southwesterly flow) in Northern Hemisphere winter (Seager et al. 2002).

A traditional and powerful tool used to study the planetary-scale effect of these forcings is the stationary wave model. Such models typically linearize the primitive equations around a prescribed flow field (e.g., the zonal mean flow for the Northern Hemisphere winter). Heating and orographic anomalies are then introduced and the steady-state response in the flow diagnosed. This method has been used to great effect by many authors (e.g., Held et al. 2002; Valdes and Hoskins 1989; Nigam 
et al. 1986; Hoskins and Karoly 1981). However, these models have three principal limitations. First, the imposed heating fields somewhat prescribe rather than predict the position and intensity of the storm tracks. Second, there is not necessarily a clear relationship between the prescribed heating fields and the features of the planetary surface (i.e., it is difficult to relate surface boundary condition anomalies to prescribed atmospheric heating anomalies). Third, traditional stationary wave models have not included nonlinear feedbacks, which are particularly important in considering the impact of heating in the presence of orography. It is therefore necessary to develop a more sophisticated modeling technique to directly relate the surface features to the storm track responses.

More recently, GCM experiments have been designed to examine the tropospheric response to boundary condition forcings. Typically, this has been implemented in one of two ways:

(i) particular features are introduced or omitted from a complete, "realistic" set of lower boundary conditions (e.g., Wilson et al. 2009; Peng and Whitaker 1999; Peng et al. 1997; Kushnir and Held 1996; Manabe and Broccoli 1990; Palmer and Sun 1985); or (ii) highly idealized boundary condition features are introduced into a simple aquaplanet configuration (e.g., Brayshaw et al. 2008; Cash et al. 2005; Inatsu et al. 2003, 2002).

Each of these approaches faces significant problems in interpreting the atmospheric response to a given forcing. For realistic configurations, the difficulty is due to the complicated background state (this is illustrated by the differing responses to the same midlatitude SST anomaly introduced into different background flows in Peng et al. 1995). Conversely, in the aquaplanet framework, it is difficult to relate the rather crude features [e.g., zonal wavenumber-1 SST anomalies in Inatsu et al. (2003)] to features in the real world.

This present study is therefore intended to form a bridge between the two complimentary approaches. The model is a full atmospheric GCM, run initially as a zonally symmetric aquaplanet and then with increasingly complex lower boundary conditions to produce a "semirealistic" planet including an idealized North America, South America, Eurasia, and Rocky Mountains, as well as semirealistic SSTs in the North Atlantic (the response to these SST features is discussed in a subsequent paper). By performing a matrix of experiments, the response of the features can be identified and traced through a hierarchy of complexity.

It should be noted that this list of boundary condition features is not intended to be exhaustive and that many other features (such as the Himalayas and the western Pacific warm pool) can have impacts on the flow in the North Atlantic sector. These remote features can, however, be expected to have a rather more subtle effect on the North Atlantic flow than the more proximate features discussed in this study.

In this paper, the design of the experiments and the results of a zonally symmetric aquaplanet control run are presented in section 2. Section 3 discusses a series of experiments featuring highly idealized continental landmasses and orography. Section 4 applies the results of the earlier sections to a series of semirealistic experiments featuring shaped continents and orography. A summary of the conclusions is presented in section 5 . The diagnostic techniques used are described in the appendix, including a discussion of the scalings used to normalize the vertical and horizontal components of the E vector (see also Brayshaw et al. 2008 and Hoskins et al. 1983).

\section{Experimental design}

\section{a. The model configuration}

The Hadley Centre Atmosphere Model HadAM3 is used to generate a number of simulations featuring idealized and semirealistic boundary conditions. The model is described in detail by Pope et al. (2000) and has been used extensively within the research community. It is a hydrostatic gridpoint model with an Eulerian advection scheme and includes a full set of parameterizations. The standard model configuration has a resolution of N48L19 $\left(2.5^{\circ}\right.$ latitude $\times 3.75^{\circ}$ longitude with 19 vertical levels), but throughout this paper a resolution of N96L30 $\left(1.25^{\circ}\right.$ latitude $\times 1.875^{\circ}$ longitude with 30 vertical levels) is used. While the standard resolution has been found to reproduce the large-scale characteristics of the storm tracks quite well (Stratton 2004), the increased resolution further improves this representation. In particular, the change from N48 to N96 produces an increase in the strength of the storm tracks and their position is shifted poleward, leading to better agreement with observations (Stratton 2004; Greeves et al. 2007; Pope and Stratton 2002).

Each integration contains $5 \mathrm{yr}$ of data (10 $\mathrm{yr}$ for the control integration) following an initial spinup period and is performed under perpetual equinox conditions. The removal of the seasonal cycle allows significant differences in the model response to be observed using shorter integrations and the use of equinoctial conditions reduces the risk of producing excessively cool continental areas at high latitudes (for perpetual solstice conditions, areas near the pole would receive would very 

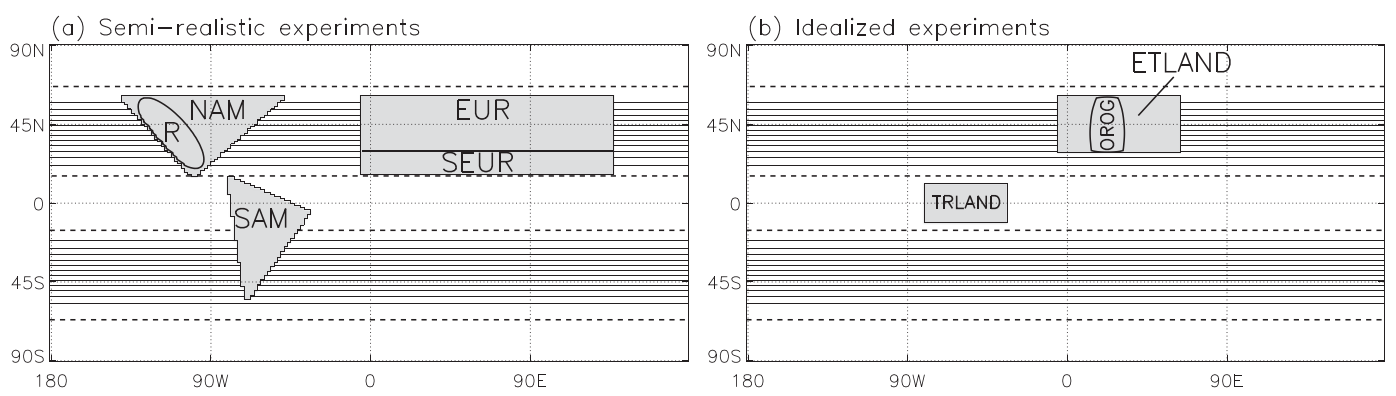

FIG. 1. The surface boundary conditions used for the experiments. Contours show SST (interval is $2^{\circ} \mathrm{C}$, dashed at $0^{\circ}$ and $26^{\circ} \mathrm{C}$ ) and shaded areas indicate landmasses. The dark curved contours indicate $500 \mathrm{~m}$ above sea level. (a) The semirealistic $3 \mathrm{C}+\mathrm{R}$ experiment. (Experiment $3 \mathrm{C}$ is identical to this but without the orography " $\mathrm{R}$." Experiment $2 \mathrm{C}$ is identical to 3C except that it lacks the landmass SAM. Experiment 3C-SEUR is identical to experiment 3C but has the southern edge of the EUR continent removed.) (b) The idealized landmasses and orography. Note that, for the idealized experiments, only one of the two continents (TRLAND and ETLAND) is included at any one time.

little insolation). Furthermore, for experiments with hemispherically symmetric boundary conditions, perpetual equinox conditions allow the two hemispheres to be combined to double the effective length of the time series.

The boundary conditions used in the integrations are shown in Fig. 1 and a list of the integrations is provided in Tables 1 and 2.

The background SST profile is zonally symmetric and is a broader and warmer version of the "QOBS" profile described by Neale and Hoskins (2000a) and as used by the Aquaplanet Experiment-Atmospheric Model Intercomparison Project (APE-AMIP). This profile is chosen to mimic the curvature of the zonally averaged SST of the Northern Hemisphere oceans in the winter [December-February (DJF)] period and is given by

$\mathrm{SST}=\frac{T_{\max }}{2}\left[2-\sin ^{4}\left(\frac{90}{67} \phi\right)-\sin ^{2}\left(\frac{90}{67} \phi\right)\right]$,

where $T_{\max }=28.0^{\circ} \mathrm{C}$ and $\phi$ denotes the latitude. At latitudes above $67^{\circ}$, the SST is set to $0^{\circ} \mathrm{C}$ (there is no sea ice represented anywhere in the model). Hereafter, this SST distribution is known as QOBSWIDE.

Land surface areas are prescribed to have homogeneous soil and vegetation properties across each continent, but the soil temperature and moisture are allowed to evolve freely. The soil and vegetation properties are created by taking an existing land surface point from a full realistic set of surface boundary conditions and copying those properties into each point of the idealized landmass. For the "North American," "Eurasian," and idealized extratropical landmasses, the representative point is $0^{\circ}, 52.5^{\circ} \mathrm{N}$ (which roughly corresponds to the United Kingdom), whereas for the "South American" and idealized tropical landmass the representative point is $5.0^{\circ} \mathrm{S}, 292.5^{\circ} \mathrm{E}$ (tropical rain forest in the Amazon Basin).
All of the idealized continents have height and roughness and are capable of stimulating gravity wave drag.

The mountainous region marked " $R$ " in Fig. 1a is designed to mimic the Rocky Mountains, both in orientation and size. The mountain is a rotated Gaussian bump constructed such that the area average of the orographic parameters (roughness, height, gravity wave drag) in the bump matches that of the Rocky Mountains as prescribed in the fully realistic surface boundary conditions for the same model. The orography in experiment OROG (Fig. 1b) is identical but is not rotated.

The suitability of the choices made here can be demonstrated by comparing the climatology of a "most realistic" idealized experiment to that produced by the same model using climatological forcings. It is found that the gross features of the North Atlantic storm track, such as its localization over the ocean basins and the southwest-northeast tilt in the North Atlantic, are well represented. This will be discussed in more detail in a

TABLE 1. The semirealistic experiments. Column key: HemSym = boundary conditions are symmetric about the equator; $\mathrm{NHC}=$ Northern Hemisphere continents [North America (NAM) and Eurasia (EUR)]; SAM = South American continent; R = Rocky Mountains; SEUR $=$ southern edge of Eurasian continent (see Fig. 1a). The column "Years" refers to the number of years of data following an initial spinup period. All experiments use the QOBSWIDE profile as their background state to which anomalies are then added.

$\mathrm{NHC}$

Experiment HemSym Years (NAM+EUR) SAM R SEUR

\begin{tabular}{llrlllll}
\hline QOBSWIDE & $\mathrm{Y}$ & 10 & & & & & \\
$2 \mathrm{C}$ & $\mathrm{N}$ & 5 & $\mathrm{Y}$ & & & $\mathrm{Y}$ \\
$2 \mathrm{C}+\mathrm{R}$ & $\mathrm{N}$ & 5 & $\mathrm{Y}$ & & $\mathrm{Y}$ & $\mathrm{Y}$ \\
$3 \mathrm{C}$ & $\mathrm{N}$ & 5 & $\mathrm{Y}$ & $\mathrm{Y}$ & & $\mathrm{Y}$ \\
$3 \mathrm{C}-S E U R$ & $\mathrm{~N}$ & 5 & $\mathrm{Y}$ & $\mathrm{Y}$ & & \\
$3 \mathrm{C}+\mathrm{R}$ & $\mathrm{N}$ & 5 & $\mathrm{Y}$ & $\mathrm{Y}$ & $\mathrm{Y}$ & $\mathrm{Y}$
\end{tabular}


TABLE 2. The idealized landmass experiments. All experiments use the QOBSWIDE profile as their background state to which anomalies are then added.

\begin{tabular}{|c|c|c|c|}
\hline Experiment & HemSym & Years & Description \\
\hline TRLAND & $\mathrm{Y}$ & 5 & $\begin{array}{l}\text { Small landmass in the } \\
\text { tropics only }\end{array}$ \\
\hline ETLAND & $\mathrm{N}$ & 5 & $\begin{array}{l}\text { Small landmass in the } \\
\text { extratropics only }\end{array}$ \\
\hline OROG & $\mathrm{N}$ & 5 & $\begin{array}{l}\text { As in ETLAND but also } \\
\text { including a mountain }\end{array}$ \\
\hline
\end{tabular}

subsequent paper based on Brayshaw (2006), in which the impacts of zonally asymmetric SST distributions that mimic the North Atlantic are discussed. The idealized experiments presented here (TRLAND, ETLAND, and OROG) are used to provide insight into the basic processes involved.

\section{b. The control run}

The axisymmetric basic state, including the storm track, produced in the control integration (driven by the QOBSWIDE SST profile) is shown in Fig. 2. The equatorial rainfall maximum is split into two maxima, one on either side of the equator (not shown). The tropospheric jet displays both a baroclinic component immediately on the poleward side of the Hadley cell (around $30^{\circ} \mathrm{N}$ with peak intensity at $200 \mathrm{mb}$; Fig. 2a) and a more barotropic component associated with the peak in the midlatitude eddy transports (around $40^{\circ}-45^{\circ} \mathrm{N}$; Fig. $2 \mathrm{c}$ ).

The regions of strongest baroclinicity [measured by the Eady growth rate following Hoskins and Valdes (1990)] display indications of double maxima (Fig. 2b). The first is seen most clearly in the upper troposphere at approximately $20^{\circ}-30^{\circ}$ and is associated with the subtropical jet. The second occurs at around $40^{\circ}-50^{\circ}$ and is most clearly seen in the lower troposphere and is associated with the SST gradients immediately underlying the region. Eddy activity occurs most strongly over the latter of these two maxima, with the normalized vertical component of the $\mathbf{E}$ vector (i.e., a scaled poleward heat flux as discussed in the appendix) peaking at around $45^{\circ}-50^{\circ}$ latitude (Fig. 2c).

The thermal transport associated with the storm track suggests that the eddies could support surface westerly winds on the order of 6-7 $\mathrm{m} \mathrm{s}^{-1}$, whereas the momentum fluxes suggest a value closer to $3-4 \mathrm{~m} \mathrm{~s}^{-1}$ at $45^{\circ}$ latitude (the method used to estimate these values is discussed in the appendix). These two estimates are broadly consistent with each other because the relative impact of the thermal transport is expected to be an overestimate $\left(E_{p}\right.$ does not go to zero at the surface). Furthermore, the observed surface wind at $45^{\circ}$ of nearly $10 \mathrm{~m} \mathrm{~s}^{-1}$ (Fig. 2a) is consistent with both these estimates because the total
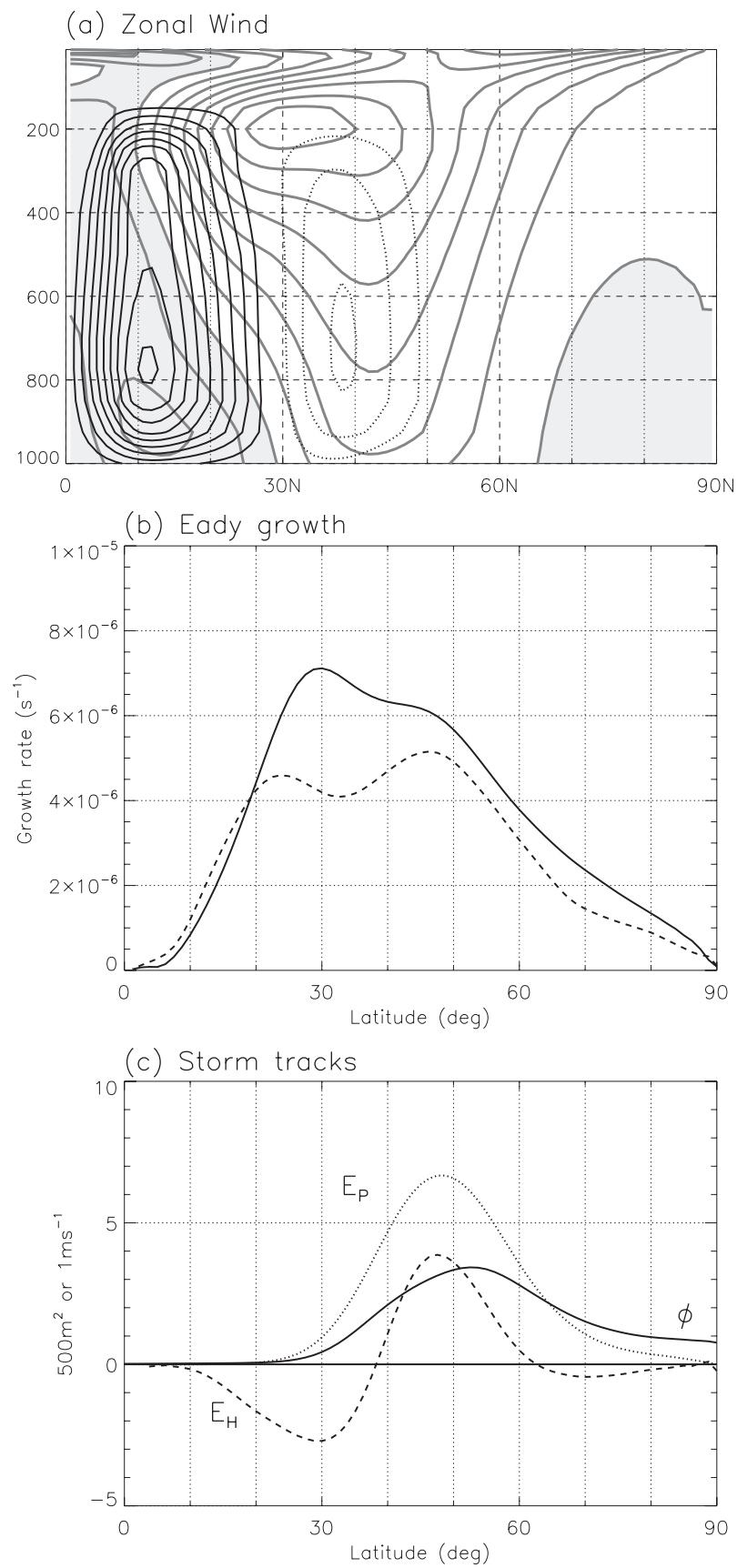

FIG. 2. The control run with the zonally symmetric boundary conditions (QOBSWIDE). (a) Zonal wind [thick gray contours; contour interval $(\mathrm{CI})=5 \mathrm{~m} \mathrm{~s}^{-1}$, negative values shaded] and zonal mean meridional circulation (black contours; $\mathrm{CI}=2 \times 10^{10} \mathrm{~kg} \mathrm{~s}^{-1}$, dashed for negative). (b) Eady growth rates measured between 925-250 (solid) and 925-775 hPa (dashed). (c) Storm track diagnostics: Bandpass-filtered geopotential height variance at $850 \mathrm{hPa}$ (solid) and normalized $\mathbf{E}$ vector (vertical component at $850 \mathrm{hPa}$ is shown by the dotted line and horizontal divergence at $250 \mathrm{hPa}$ is shown by the dashed line); see the appendix for a discussion of $\mathbf{E}$ vector normalization. 
(i.e., unfiltered) eddy fluxes are typically double the magnitude of the bandpass-filtered values shown in Fig. 2c.

The strength and position of the jet is comparable to that seen in the transition seasons in the 40-yr European Centre for Medium-Range Weather Forecasts (ECMWF) Re-Analysis (ERA-40) (Uppala et al. 2005), although it is weaker than the peak intensities seen in the wintertime northern Pacific or Atlantic. This reduced strength can be attributed to a combination of the equinoctial boundary conditions that are used here and the lack of zonal asymmetry. Furthermore, the structure of the tropospheric jets and the baroclinicity suggests that although the troposphere is generally residing in a single jet state it is extremely close to producing a separation between the two components and is therefore likely to be highly sensitive to changes in either the strength of the Hadley circulation or the surface temperature gradients in the midlatitudes (this is discussed in more detail in Brayshaw et al. 2008).

\section{Idealized simulations}

\section{a. Extratropical land}

The response to the idealized extratropical landmass in the experiment ETLAND is shown in Fig. 3. The storm track is weakly localized on the downstream side of the continent, with the enhancement reducing as the track moves eastward from the coast (Fig. 3a). Over the continental area, the storm track is suppressed.

The suppression of the storm track over the continent (Fig. 3a) is consistent with the increased surface drag $^{1}$ and the reduced latent heat availability in the atmosphere (consistent with the reduced evaporation and precipitation in Fig. 4a).

In contrast to the weakened storm track, the continental interior displays strong baroclinicity in the lower troposphere (Fig. 3b). This reflects the intensified meridional gradients in the surface temperature over the continent (not shown), which are supported by the latitudinal differences in solar radiation (recall that the model has prescribed SSTs but the land surface temperature is freely evolving).

Latitudinal differences in soil moisture availability act to further amplify the surface meridional temperature gradients in the southern part of the continent. South of approximately $35^{\circ}-40^{\circ} \mathrm{N}$, there is shift toward sensible heating of the atmosphere (rather than evaporation and latent heating under the storm track region around $45^{\circ}-50^{\circ} \mathrm{N}$; Fig. $4 \mathrm{a}$ ) that acts to further amplify the near-

\footnotetext{
${ }^{1}$ The damping time scale over land is approximately half that over the ocean. This compares with an enforced ratio of one quarter in Rodwell and Hoskins (1996).
}

surface temperature gradients. These gradients in soil moisture are consistent with the relatively weak precipitation (and therefore low soil moisture) south of $35^{\circ}-40^{\circ} \mathrm{N}$ (Fig. $4 \mathrm{a}$ ) compared to the stronger precipitation under the storm track, which acts to maintain a moderate level of soil moisture there.

Although the region of strong baroclinicity in the continental interior does not produce a strengthening of the storm track as indicated by the variance of the geopotential height at $850 \mathrm{hPa}$ (Fig. 3a), it does lead to intense eddy heat fluxes in the lowest few kilometers of the atmosphere (as indicated by the vertical component of the $\mathbf{E}$ vector; Fig. 3c). The shallow nature of these eddies is likely to be related to the absence of an evaporative source over the southern part of the continent and, consequently, the switch to surface sensible heating of the atmosphere (rather than surface latent heating) as shown in Fig. 4a. This is consistent with reduced condensation and latent heat release in the midtroposphere (which would normally act to deepen the storm).

The enhanced meridional thermal contrast forced by the strong surface heat fluxes on the equatorward portion of the continent is somewhat reduced by the enhanced near-surface poleward eddy transport of heat. The enhanced thermal wind is then consistent with the reduced surface westerlies that are forced by the enhanced drag over the land.

The westerly flow acts to advect the enhanced thermal contrast over the ocean to the east. The confluence near the east coast of the continent (at $45^{\circ} \mathrm{N}, 60^{\circ} \mathrm{E}$ ) associated with the reduced low-level westerlies (Fig. 4b) acts to enhance the thermal contrast in the western ocean basin. Over the ocean there is a renewed source of moisture and eddies are able to grow through the full depth of the troposphere, producing the intensified storm track shown in Fig. 3a. This "full depth" oceanic storm track occurs slightly to the north of the region of strongest continental baroclinicity and eddy activity, suggesting that although the "shallow" continental storm track could be acting to seed the deeper oceanic storm track, it may not be the case that individual shallow continental eddies deepen when they reach the coast.

The changes in the westerly flow of the upper troposphere (Fig. 3d), however, are more complex. Over the continent, deep eddy activity is suppressed, consistent with the jet structure shifting southward and becoming more dominated by its subtropical jet component. Downstream of the continent, where deep eddy activity increases (Fig. 3c), there is a consequent northward shift of the jet as its eddy-driven component is restored, leading to the overall jet structure downstream of the land appearing to have a very slight southwest-northeast tilt. Interestingly, the storm track and eddy-driven jet component appear 
(a) Geopotential height variance $850 \mathrm{hPa}$

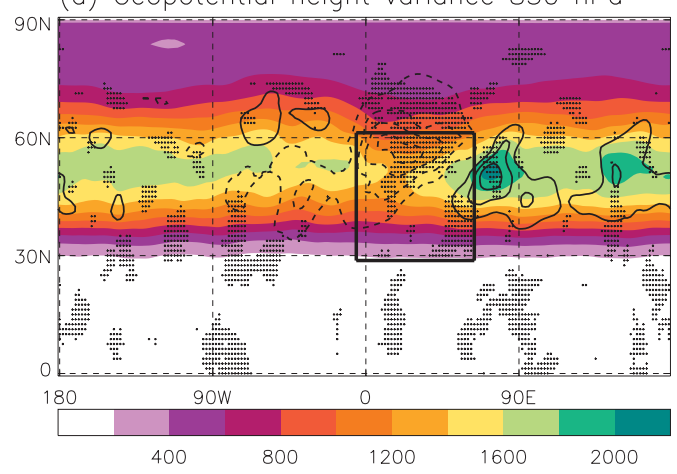

(c) Normalised E-vector

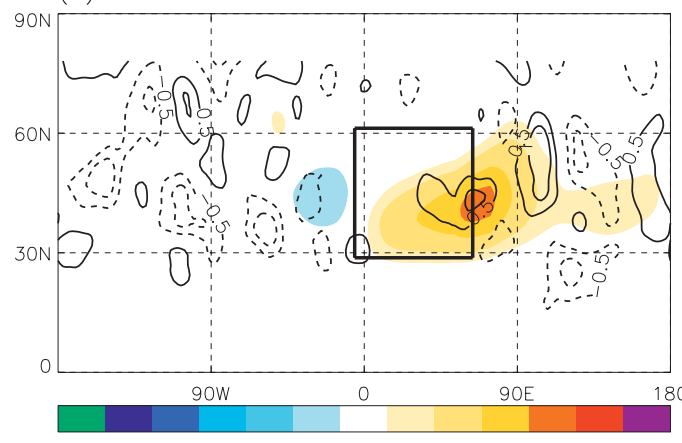

(b) Eady $850 \mathrm{hPa}$

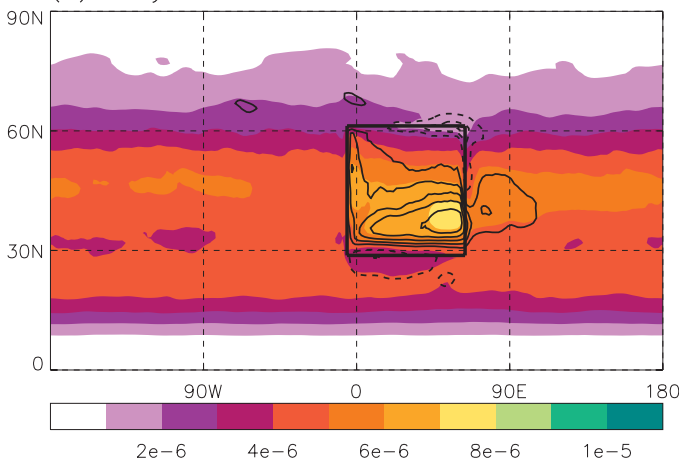

(d) Zonal wind

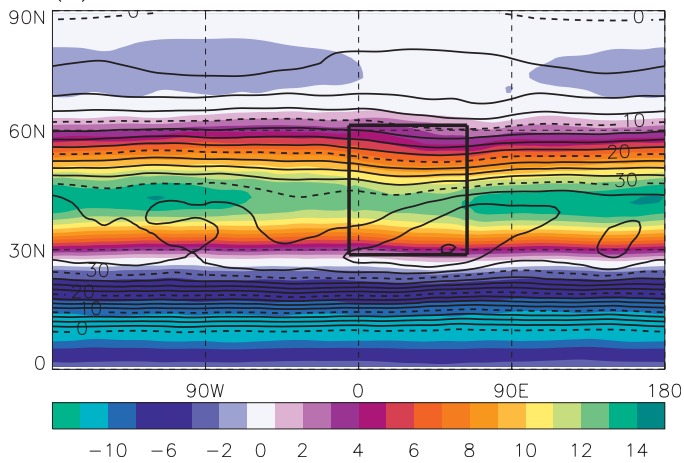

FIG. 3. Experiment ETLAND showing full fields and differences from the QOBSWIDE control run. (a) Bandpassfiltered geopotential height variance at $850 \mathrm{hPa}$ (colors), and differences (contours; $\mathrm{CI}=200 \mathrm{~m}^{2}$, dashed for negative) with areas that are significantly different at the $90 \%$ level hatched. (b) Eady growth rate at $850 \mathrm{hPa}$ (colors) and differences (contours; $\mathrm{CI}=0.5 \times 10^{-6} \mathrm{~s}^{-1}$, dashed for negative). (c) Normalized $\mathbf{E}$ vector differences: Vertical component at $850 \mathrm{hPa}$ (colors; $\mathrm{m} \mathrm{s}^{-1}$ ) and horizontal divergence at $250 \mathrm{hPa}$ (contours; CIs indicated by color, $\mathrm{m} \mathrm{s}^{-1}$ ); see the appendix for discussion. (d) Zonal wind: 850 (colors) and $250 \mathrm{hPa}$ (contours, $\mathrm{CI}=2.5 \mathrm{~m} \mathrm{~s}^{-1}$, dashed at 0,10 , $\left.20,30,40,50 \mathrm{~m} \mathrm{~s}^{-1}\right)$.

to weaken somewhat upstream of the continent, consistent with a weak Rossby wave of low zonal wavenumber that propagates westward and upward forced by the land surface (not shown).
There are also indications of two weak stationary Rossby waves propagating eastward and equatorward (entering the subtropics at $90^{\circ}$ and $160^{\circ} \mathrm{E}$, respectively), which can be seen in the upper tropospheric winds in
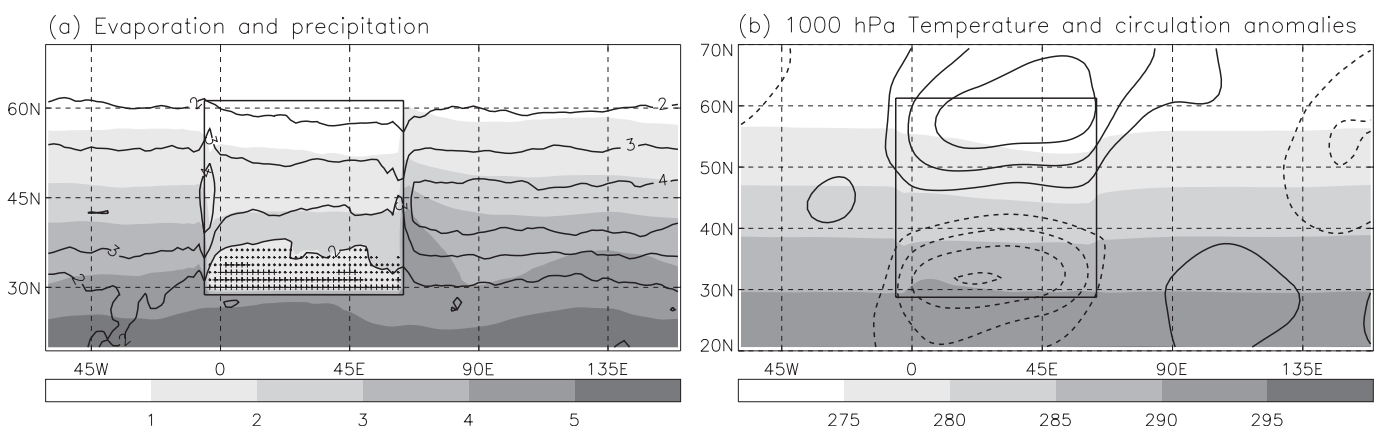

FIG. 4. Experiment ETLAND. (a) Evaporation (shading; $\mathrm{mm} \mathrm{day}{ }^{-1}$ ) and precipitation (contours; $\mathrm{mm} \mathrm{day}^{-1}$ ). Areas where the surface sensible heat flux into the atmosphere exceeds 20 and $40 \mathrm{~W} \mathrm{~m}^{-2}$ are marked with small and large plus symbols respectively. (b) Temperature (shading; K) and zonally asymmetric streamfunction (contours at $\pm 0.5,1,1.5,2 \times 10^{6} \mathrm{~m}^{2} \mathrm{~s}^{-2}$; dashed for negative) at $1000 \mathrm{hPa}$. 
Fig. 3d. The wave also has a westward tilt with height (not shown), indicating vertical propagation from a source at or near the surface.

The storm track response to the land surface asymmetry is therefore significant but fairly weak, with a suppressed storm track over land and an enhancement downstream, consistent with the physical arguments presented above. The overall zonal asymmetry of the storm track in experiment ETLAND is similarly small but detectable (see Table 3), suggesting that extratropical landsea contrast can play a significant role in controlling the zonal distribution of the storm tracks.

\section{b. Tropical land}

The response to the idealized tropical landmass is shown in Fig. 5. In general, the storm track changes are small (Fig. 5a) with a general weakening of storm activity relative to the control run centered at approximately $60^{\circ} \mathrm{N}$ (between $90^{\circ} \mathrm{W}$ to $120^{\circ} \mathrm{E}$ ), although there are indications that the change can be interpreted as more of an equatorward shift (most clearly seen near $45^{\circ} \mathrm{W}$ ) rather than simply a reduction in activity. There are similar changes in the normalized E-vector components (Fig. 5c) suggesting that changes in eddy activity may exert some feedback on the storm track (but that this is rather weak).

These changes in the storm track cannot be understood solely in terms of extratropical processes as the surface boundary conditions of the extratropics are identical to those in the control integration. There is therefore little change in the lower tropospheric baroclinicity relative to the control run (Fig. 5b), although there is a slight increase coincident with the enhanced storm activity near $45^{\circ} \mathrm{N}, 45^{\circ} \mathrm{W}$. This enhanced storm activity, as shown in Fig. $5 \mathrm{c}$, is consistent with the structure of the lower tropospheric zonal wind (Fig. 5d) and in particular the enhancement of $1-2 \mathrm{~m} \mathrm{~s}^{-1}$ at $45^{\circ} \mathrm{N}$, $\left.45^{\circ} \mathrm{W}\right)$. The structure of the zonal wind in the upper troposphere (Fig. 5d), however, cannot be explained by changes in the eddy heat and momentum transports. To understand this fully it is necessary to examine the tropical response to the landmass.

The tropical response to the landmass is shown in Fig. 6. Above the continent there is strong ascent (Fig. 6b), associated with anomalous heating in the midtroposphere (approx $2 \mathrm{~K} \mathrm{day}^{-1}$; Fig. 6a) due to the release of latent heat, indicated also by an increase in precipitation there (Fig. 6b). There is strong moisture convergence into the continental interior, the surface of which remains fully saturated throughout the integration. The increased surface drag over the land is also consistent with increased convergence toward the equator at low levels, acting to further increase the ascent over the landmass.
TABLE 3. Strength of the zonal asymmetry in bandpass-filtered geopotential height variance at $850 \mathrm{hPa}\left(\mathrm{m}^{2}\right)$. The values represent the strength of the storm track meridionally averaged between $30^{\circ}$ and $65^{\circ}$ latitude (areas where the mean surface pressure is lower than $850 \mathrm{hPa}$ are discarded). The maximum positive and negative zonal anomalies are also recorded. For the semirealistic experiments $2 \mathrm{C}$ to $3 \mathrm{C}+\mathrm{R}$, the region searched for the peak anomaly is restricted to the Atlantic sector $\left(135^{\circ} \mathrm{W}\right.$ to $\left.20^{\circ} \mathrm{E}\right)$. The column "Asymmetry strength" expresses the mean anomaly (i.e., [ $[\max \mid+$ $|\min |] / 2)$ for each integration as a fraction of its own zonal average.

\begin{tabular}{lcccc}
\hline Experiment & $\begin{array}{c}\text { Zonal } \\
\text { avg }\end{array}$ & $\begin{array}{c}\text { Max } \\
\text { anomaly }\end{array}$ & $\begin{array}{c}\text { Min } \\
\text { anomaly }\end{array}$ & $\begin{array}{c}\text { Asymmetry } \\
\text { strength }\end{array}$ \\
\hline QOBSWIDE & 1155 & 39 & -32 & $3 \%$ \\
TRLAND & 1131 & 77 & -50 & $6 \%$ \\
ETLAND & 1142 & 148 & -190 & $15 \%$ \\
OROG & 1027 & 286 & -360 & $31 \%$ \\
2C & 1174 & 79 & -190 & $11 \%$ \\
2C+R & 1010 & 312 & -412 & $36 \%$ \\
3C & 1181 & 73 & -221 & $12 \%$ \\
3C-SEUR & 1104 & 107 & -144 & $11 \%$ \\
3C+R & 1014 & 318 & -447 & $38 \%$ \\
\hline
\end{tabular}

The pattern of the streamfunction response in the tropics (equatorward of $30^{\circ}$ latitude) resembles that discussed by authors such as Gill (1980), Hoskins and Karoly (1981), and Ting and Held (1990). In the upper troposphere, the ascent produces vortex squashing and an anticyclonic tendency. This tendency is balanced by the advection of higher-vorticity air from higher latitudes (Fig. 6c), leading to an anticyclone pair straddling the equator somewhat to the west of the heating region (the northern half of this pair is centered on approximately $70^{\circ} \mathrm{W}$ in Fig. 6c).

This westward offset of the anticyclone pair is, however, weaker in the current experiment than that suggested by the simple linear model developed by Gill (1980), consistent with the discussion of Hendon (1986) and the background westerly flow in the subtropical upper troposphere (Jin and Hoskins 1995). The signal is broadly the first baroclinic mode in the vertical (although there is some poleward tilt with height), and a pair of cyclones can be seen to straddle the equator in the 850-hPa streamfunction field (see shading in Fig. 6c; the northern half of the pair is centered at approximately $\left.15^{\circ} \mathrm{N}, 75^{\circ} \mathrm{W}\right)$. Qualitatively, this behavior is similar to that produced in "tropical SST hotspot" aquaplanet experiments (e.g., Neale and Hoskins 2000b), although additional experiments have confirmed that the strength of the signal is much weaker than that generated in response to a $3^{\circ} \mathrm{C}$ tropical SST anomaly.

The changes in the tropical upper troposphere are consistent with the enhancement of the subtropical jet around $35^{\circ} \mathrm{N}, 45-60^{\circ} \mathrm{W}$ (Fig. $5 \mathrm{~d}$ ) and the consequent increase in the baroclinicity (Fig. 5d), particularly in the 
(a) Geopotential height variance $850 \mathrm{hPa}$

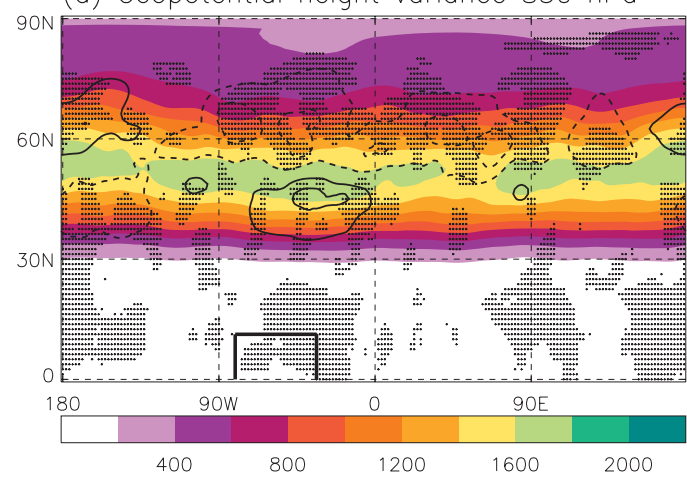

(c) Normalised E-vector

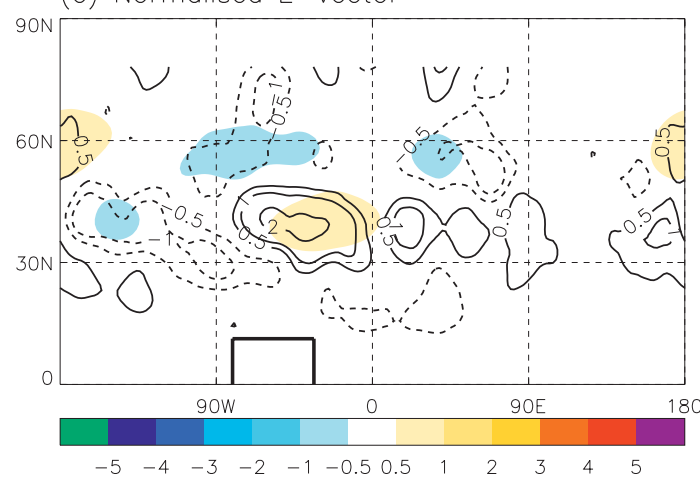

(b) Eady $850 \mathrm{hPa}$

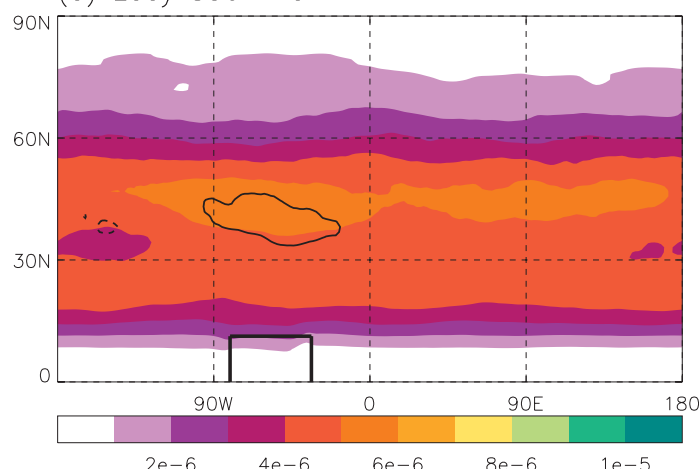

(d) Zonal wind

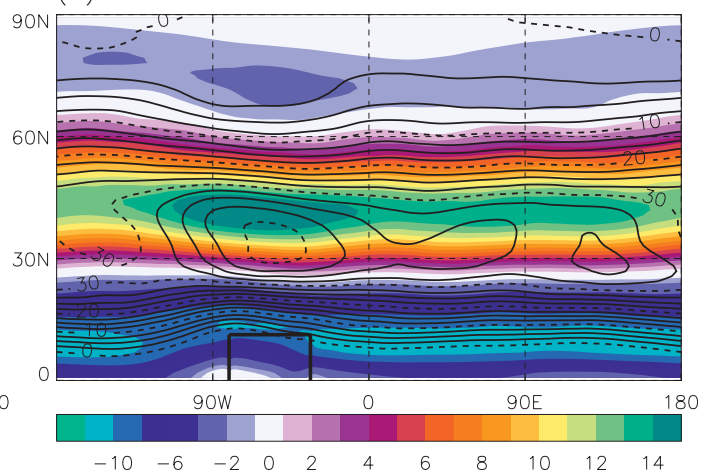

FIG. 5. As in Fig. 3, but for experiment TRLAND.

upper troposphere. The increased storm activity and near-surface zonal wind speed in the region (Figs. 5a,d) are consistent with this zonally localized increase in the Hadley circulation, as discussed in Brayshaw et al. (2008) and Nakamura et al. $(2004,2008)$. There is a local strengthening of the subtropical jet and an equatorward shift of the storm track, away from the midlatitude surface temperature fronts.

The structure of the upper tropospheric flow is also affected by Rossby waves generated by the anomalous ascent and divergence associated with the landmass. The pattern associated with these waves can be seen in Fig. $6 \mathrm{c}$ and has a generally barotropic character in the extratropics. There are suggestions of several waves propagating northeastward from $45^{\circ} \mathrm{N}, 45^{\circ} \mathrm{W}$ before curving back southeastward and splitting into at least two separate wave trains entering the tropics at approximately $90^{\circ} \mathrm{E}$ and $135^{\circ} \mathrm{E}$, respectively. There are also suggestions of some waves propagating almost zonally through the middle and high latitudes.

There is some evidence in Figs. 5a,c that the downstream modulation of the subtropical jet strength by the Rossby waves may act to further modulate the storm track (e.g., the suppressed storm track at $50^{\circ} \mathrm{N}, 60^{\circ} \mathrm{E}$, followed by the very slightly enhanced storm track at $50^{\circ} \mathrm{N}, 90^{\circ} \mathrm{E}$ ). This signal, however, is very weak and is close to the threshold of statistical significance.

\section{c. Orography}

Figure 7 shows the response to the addition of an idealized mountain to the extratropical landmass experiment (i.e., OROG-ETLAND). Adding the orography clearly suppresses the storm track and jet around most of the latitude band (Fig. 7a) but also leads to increased storm activity along a southwest-northeast axis on the downstream side of the continent. These changes are consistent with the changes in the Eady growth rate in the lower troposphere (Fig. 7b).

The lower tropospheric zonal wind (Fig. 7d) is strongest $\left(\sim 13 \mathrm{~m} \mathrm{~s}^{-1}\right)$ downstream of the continental coast (near $110^{\circ} \mathrm{E}$ ) and weakest upstream of the continent (near $45^{\circ} \mathrm{W}$ and $\sim 8 \mathrm{~m} \mathrm{~s}^{-1}$ ). This difference $\left(\sim 5 \mathrm{~m} \mathrm{~s}^{-1}\right)$ is consistent with the differences in the eddy forcing shown in Fig. 7c. The upper tropospheric winds display the characteristic southwest-northeast tilt on the downstream side of the mountain, and the zonally averaged zonal wind in the midlatitude lower troposphere is reduced (not shown), consistent with the orography exerting a net deceleration due to positive zonal pressure gradients across the mountain. This "topographic drag" 


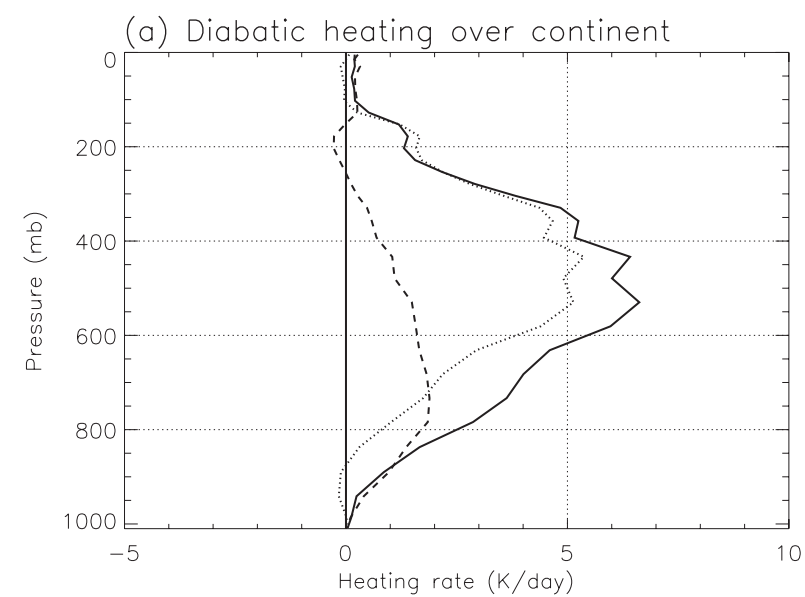

(b) Omega $500 \mathrm{hPa}$ and precipitation

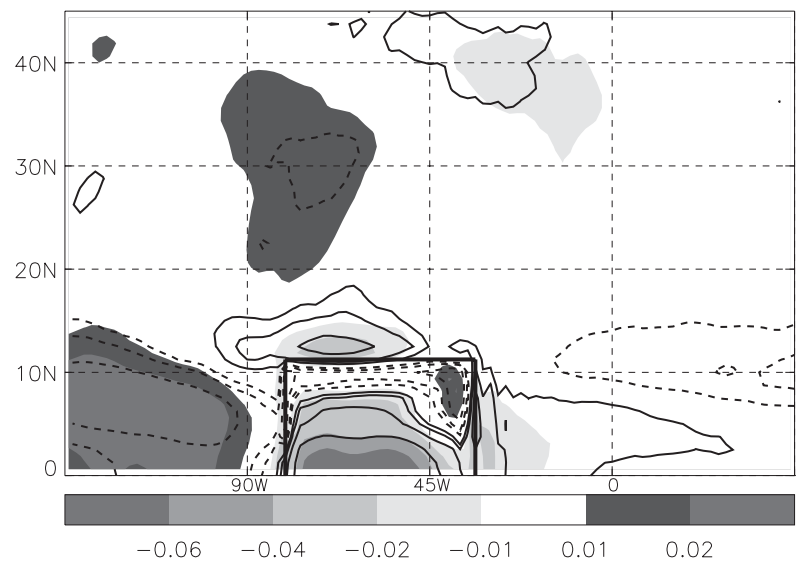

(c) Streamfunction

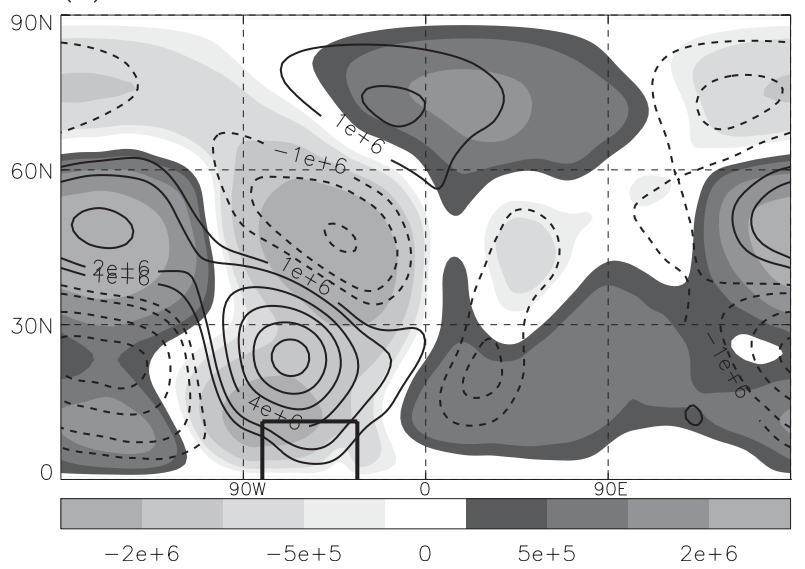

FIG. 6. The tropical response to experiment TRLAND showing full fields and differences from the QOBSWIDE control run. (a) Diabatic heating profile above the center of the continent (at $0^{\circ}$, $60^{\circ} \mathrm{W}$; solid line), for the zonal mean of the QOBSWIDE control run at the equator (dashed line), and the difference (dotted line). (b) Differences in $\omega$ at $500 \mathrm{hPa}$ (shading, negative upward, $\mathrm{Pa} \mathrm{s}^{-1}$ ) and precipitation (contours at $0.5,1,2,4 \mathrm{~mm} \mathrm{day}^{-1}$, dashed for negative). (c) Differences in the zonally asymmetric component of the streamfunction at 850 (shading) and $250 \mathrm{hPa}$ (contours, dashed for negative). of the zonal mean flow is also consistent with the reduction in the zonal mean Eady growth rate and the strength of the zonal mean storm track.

Before examining the large-scale response further, it is worthwhile considering the local response to the orography. The mountain is embedded in a region of time-mean westerly flow (Fig. 7d) and the scaling relation in Eq. (1) with characteristic values of $\bar{\theta}_{z} \approx 5 \mathrm{~K} \mathrm{~km}^{-1}$, $\bar{\theta}_{y} \approx 0.01 \mathrm{~K} \mathrm{~km}^{-1}, H \approx 2 \mathrm{~km}$, and $L \approx 3000 \mathrm{~km}$ indicates that the mountain is below the so-called critical height required to block the flow. Therefore, the air is likely to go over rather than around the mountain. This is consistent with the upstream ascent and downstream descent seen along most of the mountain (Fig. 8a).

The southern part of the mountain, however, acts as a much more effective block to the westerly flow because air that is deflected equatorward will tend to descend isentropically (because it is deflected south, it will tend to be warmer than its surroundings), thereby increasing the effective height of the orographic barrier. This is consistent with the region of descending air to the southwest of the mountain (Fig. 8a) and the generation of a cyclonic flow anomaly (due to southward advection of high-absolute vorticity air) over its southern edge $\left(30^{\circ} \mathrm{N}, 25^{\circ} \mathrm{E}\right.$ in Fig. 8b). Below approximately 800 $850 \mathrm{hPa}$ the westerly flow incident on the southern part of the mountain is completely blocked and returns as the easterlies in the subtropics (Fig. 8c). Higher in the troposphere, the southward deflection leads to an overall local response pattern more closely resembling the situation described in Ringler and Cook (1997) for mountains above the critical height threshold, with a cyclonic streamfunction anomaly occurring equatorward of the topographic anticyclone rather than downstream as in the barotropic model.

Both the cyclonic and anticyclonic anomalies extend barotropically through the depth of the troposphere, producing a strong signal of the same sign at upper levels (Fig. 9a). The net effect of the north-south anticyclonecyclone pair is to decelerate the westerly flow across the peak of the mountain region and accelerate it around the north and south. This modifies the local baroclinicity of the region, suppressing the potential for storm growth in the interior of the continent and enhancing it to the north and the southeast (Fig. 7b), consistent with the signals seen in the storm track (Figs. 7a,c). The anticyclone generated by the northern part of the mountain also advects cold air southward on the downstream side, extending the cold pool of air in that region (Fig. 8b), which acts to further enhance the baroclinicity on the downstream side of the mountain.

The orography also produces a strong response in the local precipitation (Fig. 8a). The northern half of the 
(a) Geopotential height variance $850 \mathrm{hPa}$

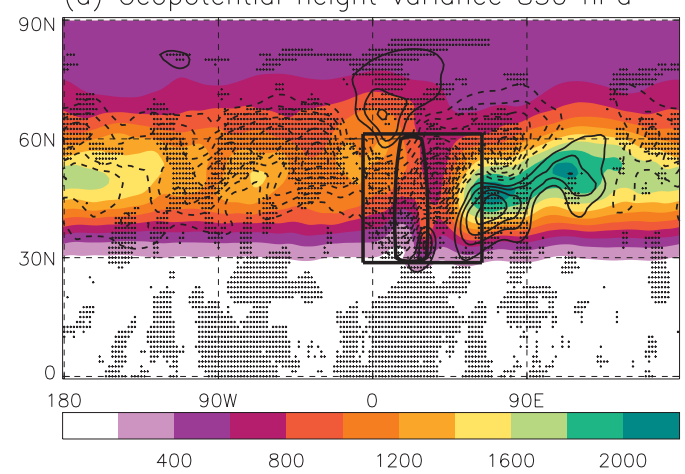

(c) Normalised E-vector

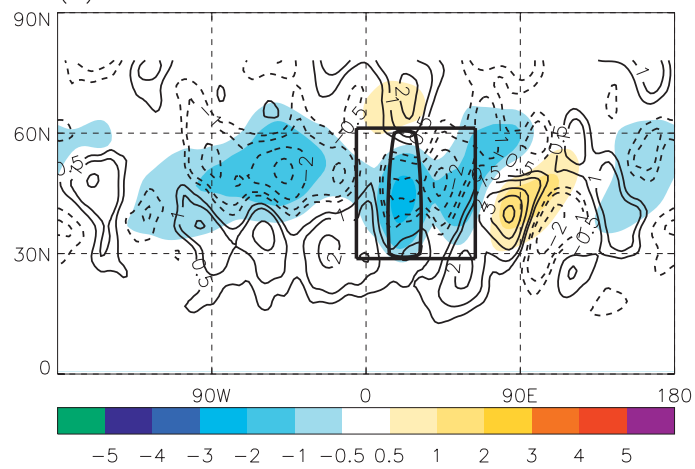

(b) Eady $850 \mathrm{hPa}$

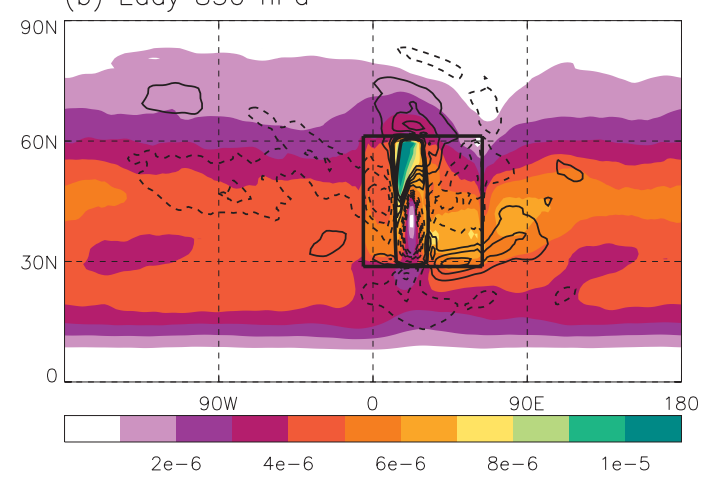

(d) Zonal wind

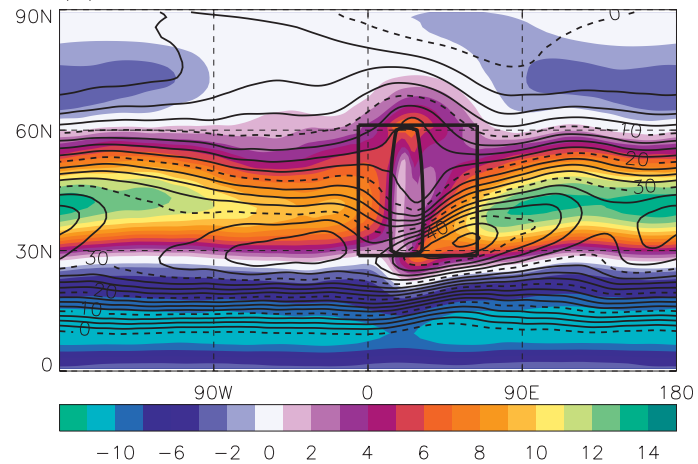

FIG. 7. As in Fig. 3, but for experiment OROG showing full fields and differences from the flat ETLAND experiment.

continent is at the same latitude as the inbound storm track from the ocean (around $45^{\circ}-60^{\circ} \mathrm{N}$ ), and in this region the ascent over the orography causes strong precipitation on the upstream face of the mountain. This leaves a rain shadow to the east, leading to reduced soil moisture availability in the northeast of the continent, consistent with the weakened storm track in that region. At lower latitudes (south of $40^{\circ} \mathrm{N}$ ) there is enhanced precipitation in the lee of the mountain and downstream to the east, consistent with enhanced ascent associated with southerly flow bringing warm, moist tropical air into the continental interior (Figs. 8a,c).

Figure 9a shows that the impact of the orography extends well beyond its immediate vicinity. In particular, there are three clear Rossby wave trains propagating eastward from the orographic region, curving southward and entering the subtropics at approximately $60^{\circ}, 120^{\circ}$, and $225^{\circ} \mathrm{E}$, respectively. Comparing the patterns in Fig. $7 \mathrm{c}$ with those in Fig. 9a reveals that the Rossby waves weakly modulate the storm track in remote regions.

The storm track response to the orographic forcing in OROG is therefore stronger than the response to the land surface forcing seen in the idealized flat continent experiment ETLAND (cf. Figs. 3a and 7a). In particular, the storm track in OROG is reduced around much of the latitude band and there is deflection around the southern part of the mountain, which helps to create a southwestnortheast tilt in the downstream flow and the storm track. Simultaneously, an anticyclonic anomaly generated by flow over the northern part of the mountain advects cold air southward on the eastern side of the mountain, generating a pool of cold and dry air and thus acting to further enhance the baroclinicity on the downstream side of the mountain.

Examination of Table 3 shows, however, that the additional zonal asymmetry in the storm track created by the orography in OROG is similar in magnitude to that created by the land surface in ETLAND. The asymmetry strength is $31 \%$ in OROG compared to $15 \%$ in ETLAND, suggesting that the land surface and orographic features each account for approximately $15 \%$ points according to this measure of storm track asymmetry.

\section{Semirealistic simulations}

\section{a. Continental-scale landmasses}

Figure 10 shows the tropospheric response to experiment $3 \mathrm{C}$ (three flat continents). There are several features that can be understood through the idealized experiments 
(a) Omega $700 \mathrm{hPa}$ and precipitation

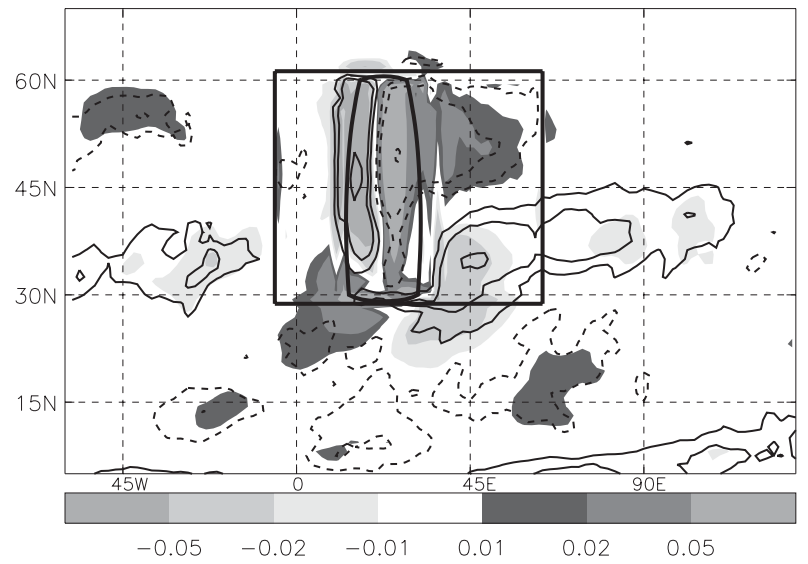

(b) Temp. and stream function anom. $700 \mathrm{hPa}$

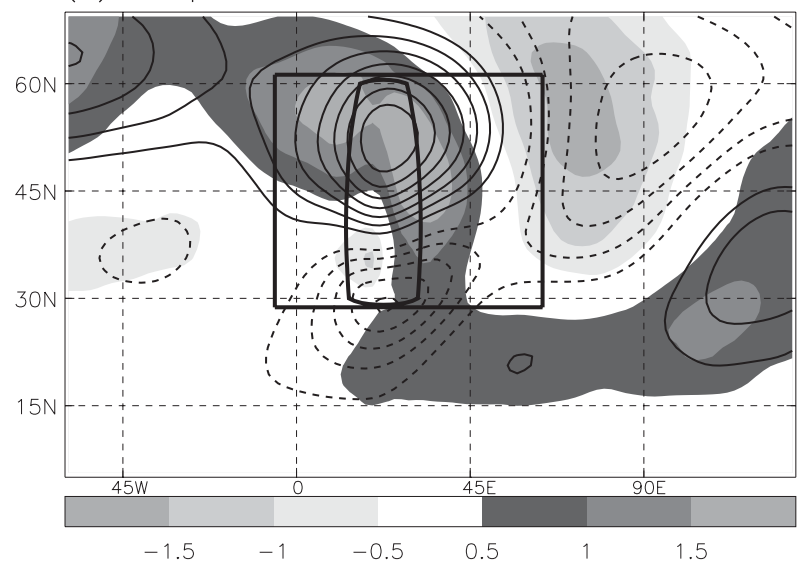

(c) Stream function $1000 \mathrm{hPa}$

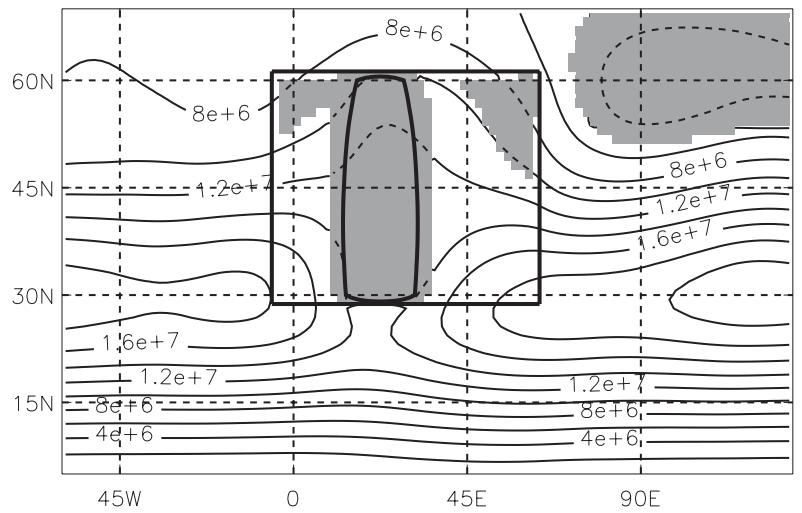

FIG. 8. The impact of the idealized mountain showing full fields and differences between OROG and ETLAND. (a) Differences in $\omega$ at $700 \mathrm{hPa}$ (shading, negative upward, $\mathrm{Pa} \mathrm{s}^{-1}$ ) and precipitation (contours at $0.5,1,2,4 \mathrm{~mm} \mathrm{day}^{-1}$, dashed for negative). (b) Differences in temperature at $700 \mathrm{hPa}$ (shading, K) and zonally asymmetric component of streamfunction at $700 \mathrm{hPa}$ (contours, $\mathrm{CI}=1 \times 10^{6} \mathrm{~m}^{2} \mathrm{~s}^{-2}$, dashed for negative) difference. (c) Full field streamfunction at $1000 \mathrm{hPa}$ (contours, $\mathrm{CI}=2 \times 10^{6} \mathrm{~m}^{2} \mathrm{~s}^{-2}$ ); areas where the surface pressure is below $1000 \mathrm{hPa}$ are shaded. presented in section 3 , but there are also some significant differences (in particular, the structure of the jet and storm track over the Eurasian continent). These differences can be primarily attributed to the southward extension of the Eurasian continent (the landmass extends farther south than in ETLAND), which is discussed separately below. The impact of the South American landmass is also discussed separately.

Consider first the structure of the storm track. Figure 10a shows that as the storm track extends eastward from an ocean basin into a landmass (either Europe or North America) it immediately weakens, consistent with the reduction in moisture availability and increased surface drag, as seen in ETLAND (Fig. 3a).

As in ETLAND, there is increased baroclinicity in the lower troposphere $\left(40^{\circ} \mathrm{N}, 90^{\circ} \mathrm{W}\right.$ and $40^{\circ} \mathrm{N}, 90^{\circ} \mathrm{E}$ in Fig. $10 \mathrm{~b}$ as opposed to $40^{\circ} \mathrm{N}, 60^{\circ} \mathrm{E}$ in Fig. 3b), consistent with increased surface temperature gradients over land areas. This baroclinicity again extends eastward, leading to an increase in the storm track over the downstream ocean (Figs. 10a and 3a).

The lower tropospheric zonal wind over the western part of the Atlantic basin is strong (Fig. 10d), consistent in location and magnitude with the enhanced storm track driving the flow there (Fig. 10c). There are also suggestions of a very weak southwest-northeast tilt to the storm track and upper tropospheric jet (similar to that seen in ETLAND), which may be related to the jet shifting from a subtropically dominated state $\left(\right.$ at $\left.100^{\circ} \mathrm{W}\right)$ to a more eddy-driven state (around $45^{\circ} \mathrm{W}$ ) as the storm track increases in intensity moving east.

\section{1) Subtropical "Eurasia"}

Over the "Eurasian" continent, the patterns produced by experiment $3 \mathrm{C}$ are more difficult to interpret directly in terms of the idealized simulations. In particular, there is a region of strong baroclinicity generated over the southwest corner of the continent (Fig. 10b) and a clear split between the subtropical and eddy-driven jet components (Fig. 10d).

This behavior can be attributed to the subtropical continental region SEUR in Fig. 1a. Examining the QOBSWIDE control run (Fig. 2a) shows that the SEUR region lies directly underneath the subtropical downwelling region of the Hadley cell. The relatively cloudfree skies and low albedo lead to strong heating of the surface by solar radiation (recall that these runs do not feature a seasonal cycle to ameliorate this heating). In the absence of a moisture source, this leads to strong sensible heating of the lower atmosphere over this section of the continent, producing dry ascent to approximately $600 \mathrm{mb}$ in the time mean (at approximately $20^{\circ} \mathrm{N}$ ). This is reminiscent of the summertime circulation over 
(a) OROG

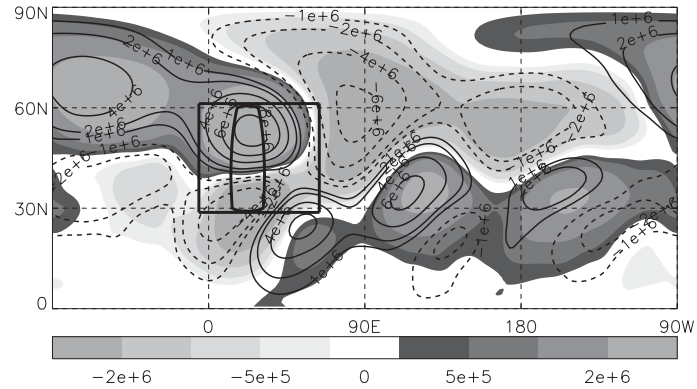

(b) $3 C+R$

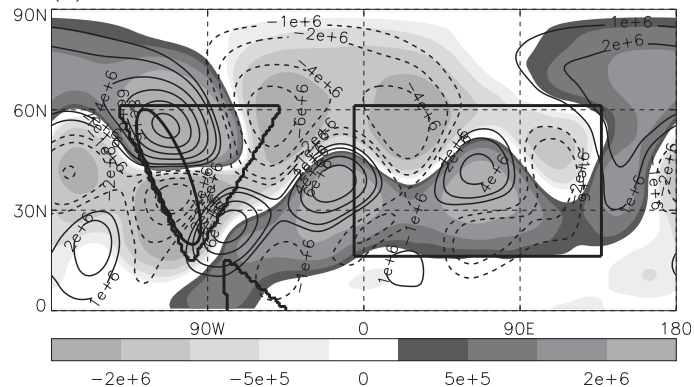

FIG. 9. Rossby wave propagation from orographic features for (a) OROG and (b) $3 \mathrm{C}+\mathrm{R}$. The anomaly in the zonally asymmetric component of the streamfunction at 850 (shading) and $250 \mathrm{hPa}$ (contours, dashed for negative) is shown relative to ETLAND in (a) and $3 \mathrm{C}$ in (b).

West Africa, where the lower tropospheric African easterly jet (AEJ) is generated by a dry overturning circulation on the equatorward flank of the Sahara in response to the contrast between the tropical ITCZ and subtropical desert (Thorncroft and Blackburn 1999; Cornforth et al. 2009). The trade wind easterlies deepen in 3C (Fig. 11a) relative to QOBSWIDE (Fig. 2a) to form an easterly wind maximum somewhat similar to the AEJ. This dry ascent disrupts the Hadley cell, causing a split in the eddy-driven and subtropical jet components over the continent in the time mean (Fig. 11a).

Repeating the experiment without this southern edge (experiment 3C-SEUR) removes this dry ascent region (Fig. 11b) and the response pattern over Eurasia becomes rather similar to that in the idealized ETLAND experiment presented previously with a single jet. The storm track seen over Eurasia in 3C (Figs. 10a,c) is reduced in 3C-SEUR, along with the baroclinicity over the continental interior (not shown). (a) Geopotential height variance $850 \mathrm{hPa}$

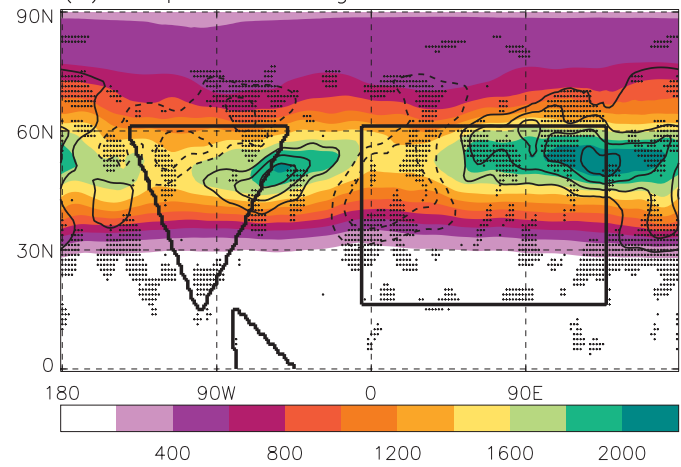

(c) Normalised E-vector

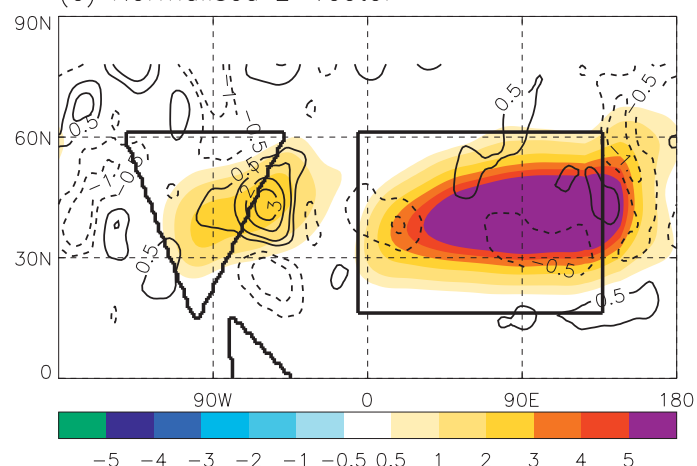

(b) Eady $850 \mathrm{hPa}$

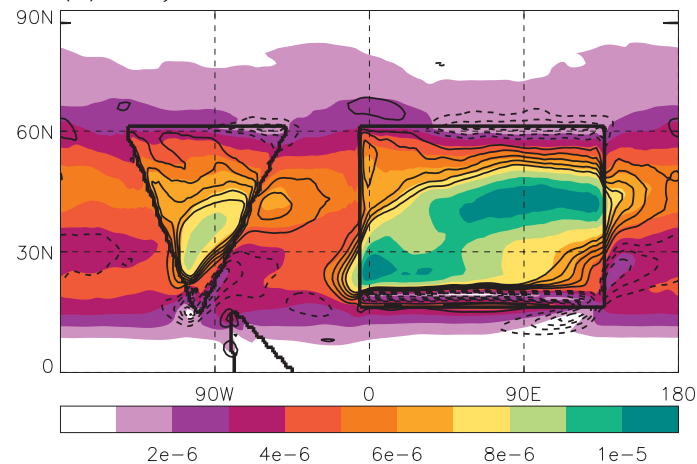

(d) Zonal wind

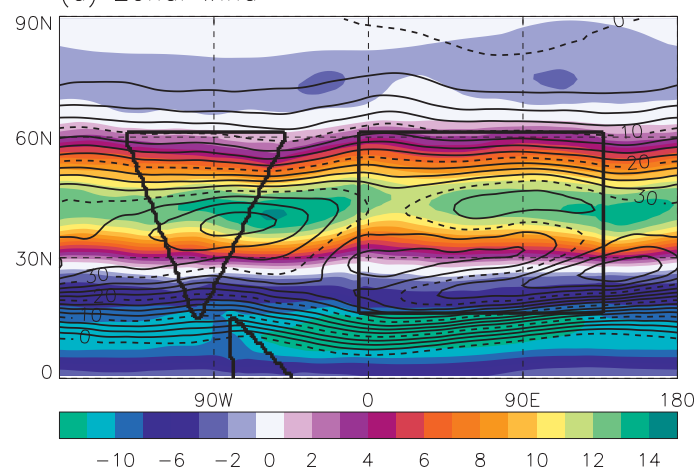

FIG. 10. As in Fig. 3, but for experiment 3C. 

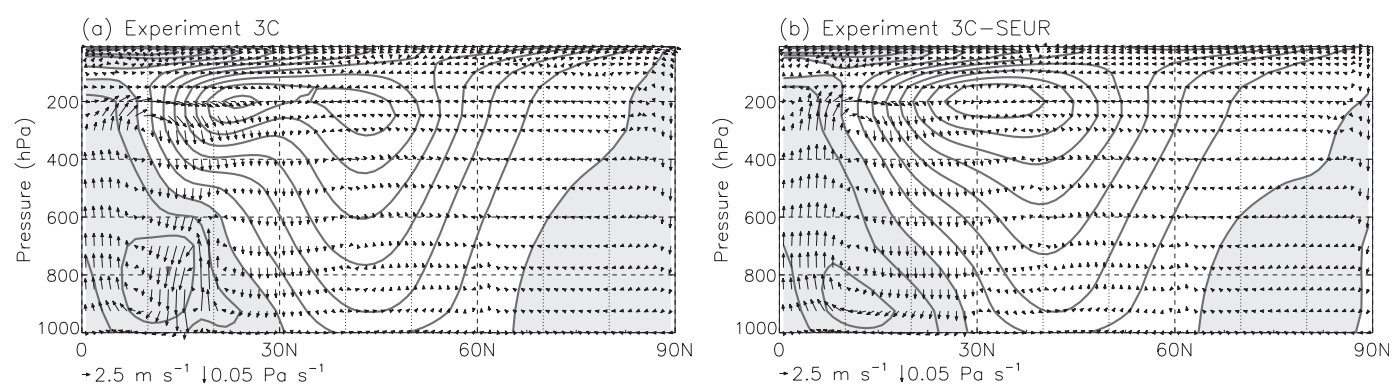

FIG. 11. The mean meridional circulation (arrows) and zonal wind (thick gray contours, $\mathrm{CI}=10 \mathrm{~m} \mathrm{~s}^{-1}$, negative values shaded) averaged over the longitude range $15^{\circ}-120^{\circ} \mathrm{E}$ for (a) $3 \mathrm{C}$ and (b) $3 \mathrm{C}$-SEUR.

There are hints that similar behavior may occur over the subtropical part of the North American continent (e.g., there is increased baroclinicity south of $30^{\circ} \mathrm{N}$ in the continental interior; Fig. 10b). This may also impact the strength of the upper tropospheric jet to the north $\left(40^{\circ} \mathrm{N}\right.$, $90^{\circ} \mathrm{W}$; Fig. 10d), although the overall affect is likely to be much weaker than that seen over Eurasia because of the smaller area of subtropical land.

\section{2) "SOUTH AMERICA"}

Consistent with the idealized experiment TRLAND, there is anomalously strong precipitation and ascent over the tropical region of South America (Fig. 12b), although the diabatic heating anomaly in the troposphere is rather weaker (approximately $3 \mathrm{~K}$ day $^{-1}$ compared to $5 \mathrm{~K} \mathrm{day}^{-1}$ in experiment TRLAND; cf. Figs. 12a and 6a).

The tropospheric flow response to this anomaly (Fig. 12c) is somewhat more complex than that shown for the idealized tropical landmass experiment (TRLAND; Fig. 6c). It is, however, possible to see an upper tropospheric anticyclone (and lower tropospheric cyclone) generated on the poleward sides of the heating region (approximately $20^{\circ} \mathrm{S}, 60^{\circ} \mathrm{W}$ and $5^{\circ} \mathrm{N}, 60^{\circ} \mathrm{W}$ in Fig. $12 \mathrm{c}$ ). Also, there are Rossby waves radiating poleward and eastward from approximately $5^{\circ} \mathrm{N}, 90^{\circ} \mathrm{W}$ (somewhat to the west of the South American continent itself) and downstream over the Eurasian continent. The Rossby waves generated in response to adding South America appear to propagate more zonally than those produced by the idealized TRLAND experiment (cf. Figs. 12c and 6c), which is probably due to disturbances in the background flow created by the Northern Hemisphere continents.

These responses act to accelerate the zonal winds across eastern North America and the North Atlantic (cf. Figs. 10d and 13d). In particular, in the northeast corner of North America there is an additional northwesterly component to the flow (Fig. 12c) bringing cooler air southward and increasing the lower tropospheric baroclinicity along the southern edge of the barotropic low centered on $45^{\circ} \mathrm{N}, 45^{\circ} \mathrm{W}$ (see Fig. $12 \mathrm{c}$ and the contours in Fig. 13b). This is consistent with increased storm activity in the region (see contours in Fig. 13a), which act to further accelerate the lower tropospheric zonal flow by $1-2 \mathrm{~m} \mathrm{~s}^{-1}$ (Fig. 13c; see also Figs. 10d and 13d). There is some evidence of changes in the storm track in remote regions due to stationary Rossby wave propagation (analogous to those seen in TRLAND), but such changes are very weak and are difficult to detect amid the background noise.

\section{b. The Rocky Mountains}

The response to adding the "Rocky Mountains" to the flat three-continent experiment is shown in Fig. 14. As in the idealized orography experiment (Fig. 7), the mountain acts to weaken the storm track and jet in the zonal mean (consistent with topographic drag). It also acts to produce a pronounced southwest-northeast tilt in the upper tropospheric jet immediately downstream of the mountain (Fig. 14d) and a marked increase in baroclinicity on the downstream side of the southern part of the mountain (approximately $35^{\circ} \mathrm{N}, 90^{\circ} \mathrm{W}$ in Fig. 14b). Consistent with this, the storm track is intensified over the downstream ocean basin along a southwestnortheast tilted axis (Fig. 14a). The eddy forcing has a similar structure (Fig. 14c) and acts to intensify the zonal wind in the lower troposphere on the downstream side of the mountain while weakening it elsewhere. The difference between the maximum and minimum eddy forcing of the zonal flow at $45^{\circ} \mathrm{N}$ is approximately $7 \mathrm{~m} \mathrm{~s}^{-1}$, which is consistent with the observed differences in the 850-hPa winds at the same latitude in Fig. 14d.

Overall, the response to the semirealistic orography appears to be rather stronger than that for the idealized orography (in terms of both the mean flow and the storm track). As discussed in section 3, each of the orographic and the extratropical landmass features in the idealized experiments led to a similar increase in the magnitude of the zonal asymmetry in the strength of the storm track (approximately $15 \%$ according to the measure defined 


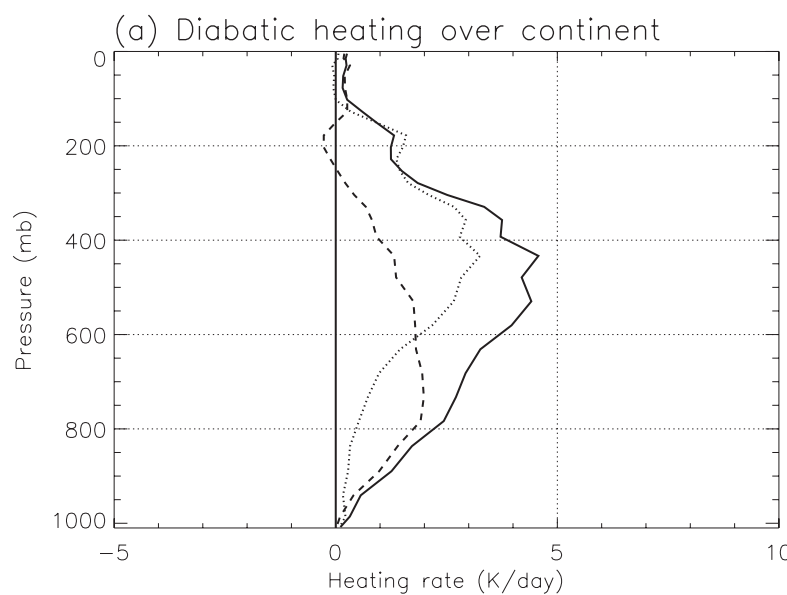

(b) Omega $500 \mathrm{hPa}$ and precipitation

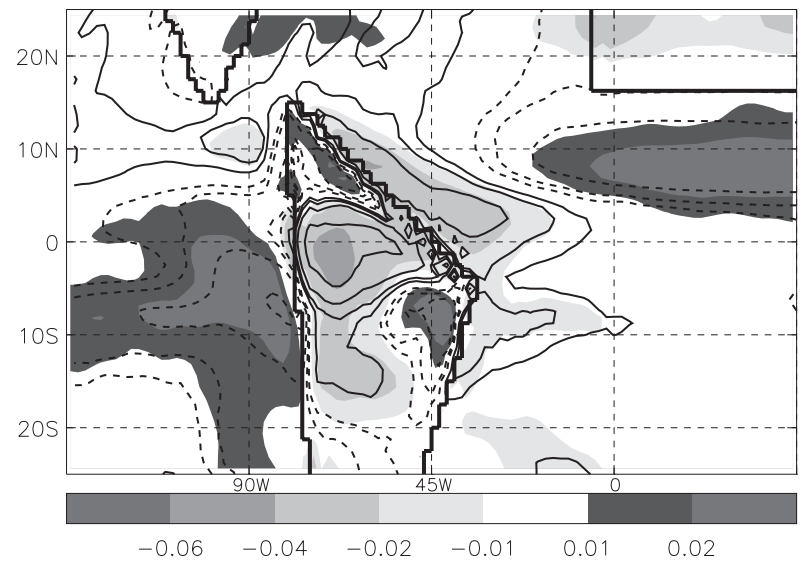

(c) Streamfunction

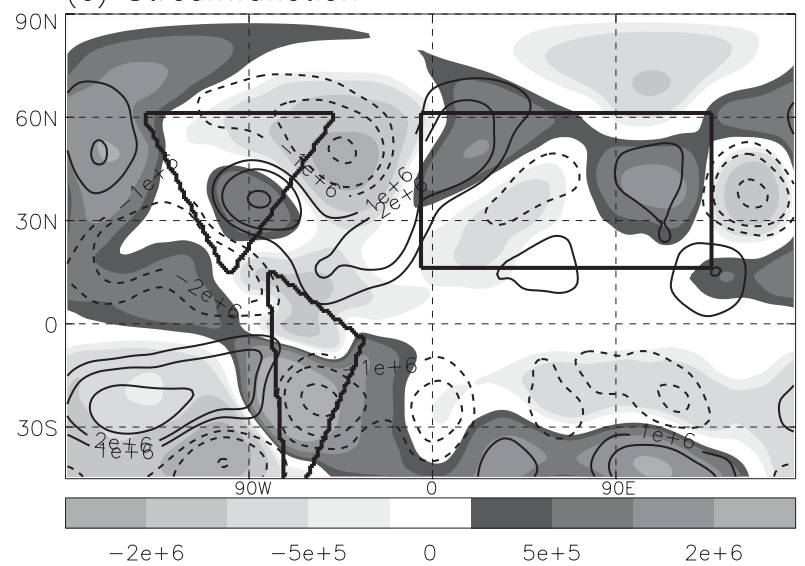

FIG. 12. The tropical response to "South America" $(3 \mathrm{C}-2 \mathrm{C})$ (a) Diabatic heating profile above $0^{\circ}, 60^{\circ} \mathrm{W}$ (solid line) and for the zonal mean of the QOBSWIDE control run at the equator (dashed line). The anomaly is shown by the dotted line. (b) Anomalous $\omega$ at $500 \mathrm{hPa}$ (shading, negative upward, $\mathrm{Pa} \mathrm{s}^{-1}$ ) and precipitation (contours at $0.5,1,2,4 \mathrm{~mm} \mathrm{day}^{-1}$, dashed for negative). (c) Anomaly in the zonally asymmetric component of the streamfunction at 850 (shading) and $250 \mathrm{hPa}$ (contours, dashed for negative). in Table 3). In the semirealistic integrations, however, the storm track strength asymmetry introduced by the "North American" continent is smaller than that from the idealized continent (around $10 \%-12 \%$ in experiments $2 \mathrm{C}, 3 \mathrm{C}$, and 3C-SEUR, consistent perhaps with the continents' smaller zonal scale at the storm track latitude), whereas the response from the "Rocky Mountains" is larger than that from the idealized mountain (around $25 \%$, leading to a total asymmetry of around $35 \%-40 \%$ in experiments $2 \mathrm{C}+\mathrm{R}$ and $3 \mathrm{C}+\mathrm{R}$ ).

The stronger orographic response can also be clearly seen by comparing the responses in the local flow patterns around the two mountain features (Figs. 15 and 8). First, the barotropic anticyclone over the northern part of the mountain and the barotropic cyclone over the south are stronger for the semirealistic mountain (cf. Figs. $15 \mathrm{~b}$ and $8 \mathrm{~b}$ ). This is consistent with the rotation of the mountain away from the north-south axis, which increases the difficulty for poleward deflected air to rise over the mountain. More air is therefore blocked and deflected equatorward. The semirealistic orography also extends farther south, consistent with further enhanced blocking of the near-surface westerlies along the southern part of the mountain (cf. Figs. 15d and 8c) and a stronger cyclonic flow anomaly there.

In the northeastern part of the continent, the additional equatorward flow leads to a larger pool of cold air (Fig. 15b). This air is also very dry because of the rain shadow effect on the downstream side of the mountain (Fig. 15a). The shape of the North American continent is such that a very large pool of cold air can develop here (larger than that in the idealized experiment OROG). The southwest-northeast tilt of the continent's eastern coastline also acts to ensure that the boundary between the cold continental air and the warm maritime air tends to align somewhat with the southwest-northeast jet axis, consistent with reinforcing the baroclinicity, the storm track, and the jet along that axis (Fig. 14).

The shape of the North American continent also means that the enhanced baroclinicity associated with the southward deflection around the mountain occurs over the ocean rather than over land (cf. Figs. 14b and $7 b)$. This ensures that storms growing in this region have a strong moisture source, consistent with a slightly stronger enhancement of the storm track in the semirealistic experiment $(3 \mathrm{C}+\mathrm{R})$ relative to the idealized experiment (OROG) (cf. Figs. 14a and 7a).

Figure $9 \mathrm{~b}$ shows the strong barotropic Rossby waves generated by the orography propagating downstream. As noted previously for the tropical landmass and South America experiments, there are suggestions that there is a greater tendency toward zonal propagation over Eurasia in the semirealistic experiment when compared 
(a) Geopotential height variance $850 \mathrm{hPa}$

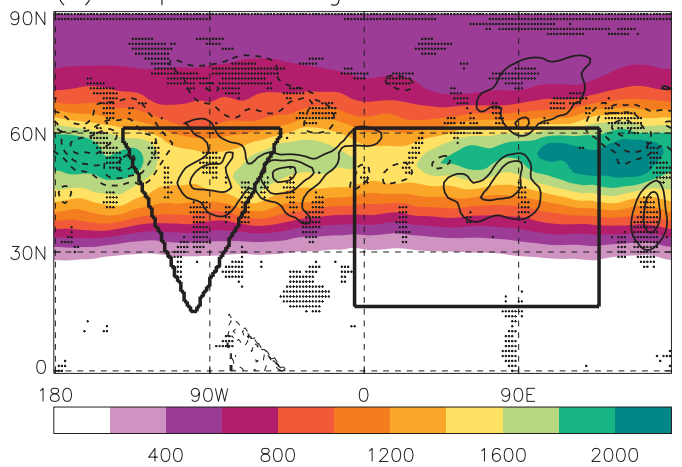

(c) Normalised E-vector

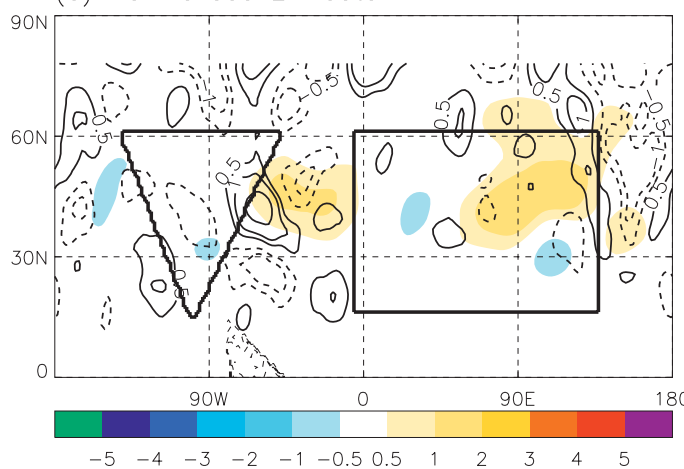

(b) Eady $850 \mathrm{hPa}$

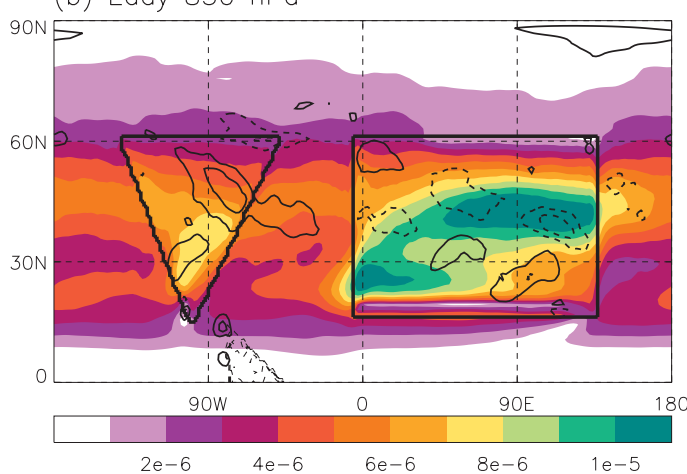

(d) Zonal wind

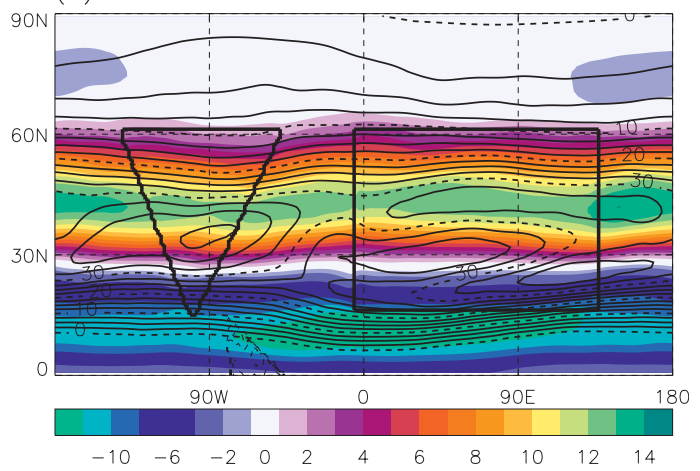

FIG. 13. Experiment $2 \mathrm{C}$ (full fields) and the differences that would be created by adding "South America" (i.e., experiment $3 \mathrm{C}-2 \mathrm{C}$ ). (a) Bandpass-filtered geopotential height variance at $850 \mathrm{hPa}$ (colors), and differences (contours, $\mathrm{CI}=200 \mathrm{~m}^{2}$, dashed for negative) with areas that are significantly different at the $90 \%$ level hatched. (b) Eady growth rate at $850 \mathrm{hPa}$ (colors) and differences (contours, CI $=0.5 \times 10^{-6} \mathrm{~s}^{-1}$, dashed for negative). (c) Normalized $\mathbf{E}$ vector differences (experiment $3 \mathrm{C}-2 \mathrm{C}$ ): vertical component at $850 \mathrm{hPa}$ (colors, $\mathrm{m} \mathrm{s}^{-1}$ ) and horizontal divergence at $250 \mathrm{hPa}$ (contours, CIs indicated by colors, $\mathrm{m} \mathrm{s}^{-1}$ ); see the appendix for discussion. (d) Zonal wind in experiment 2C: 850 (colors) and $250 \mathrm{hPa}$ (contours, $\mathrm{CI}=2.5 \mathrm{~m} \mathrm{~s}^{-1}$, dashed at 0,10, 20, 30, 40, $50 \mathrm{~m} \mathrm{~s}^{-1}$ ).

to the idealized experiment (cf. Figs. 9a,b). This suggests that the split of the upper tropospheric jet over Eurasia (generated by the SEUR region in Fig. 1a) shown in Fig. 10d is acting as a zonally oriented waveguide across the Eurasian region. It is also worth noting that the paths taken by the Rossby waves are slightly modified by the presence or absence of the South American continent (not shown).

\section{Conclusions}

This paper has presented a series of atmospheric GCM integrations designed to test the effects of landsea contrast (both midlatitude and tropical) and orography on midlatitude storm tracks and the large-scale flow patterns. The experimental configuration can be described as a "semirealistic" framework, capturing the large-scale essence of the forcing features in a full GCM while retaining conceptual simplicity. The hierarchical nature of the experiments allows more complex integrations to be interpreted in terms of simpler configu- rations, creating a bridge between simple idealized modelling studies and full "realistic" GCM integrations.

Each of the forcing mechanisms presented here has been shown to have an effect on the large-scale flow and midlatitude storm tracks and some basic statistics are given in Table 3. In particular:

- Tropical landmasses produce a response that is similar to but weaker than that of tropical SST anomalies, with increased ascent and divergent upper tropospheric flow over the landmass. Rossby wave radiation affects the flow in more remote regions of the extratropics.

- Extratropical landmasses lead to a generally suppressed storm track in the continental interior. This is consistent with the effects of increased surface drag and reduced moisture availability over the continent. Strong surface sensible heat fluxes over the equatorward portion of the continent lead to enhanced baroclinicity over the continent. Supported by enhanced confluence near the eastern coast, this enhanced 
(a) Geopotential height variance $850 \mathrm{hPa}$

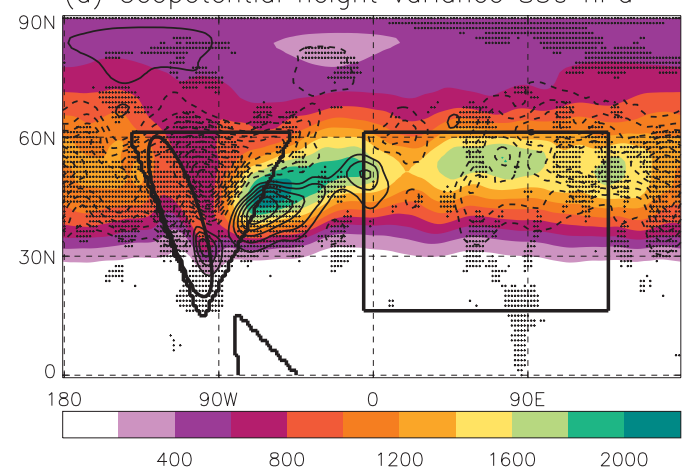

(c) Normalised E-vector

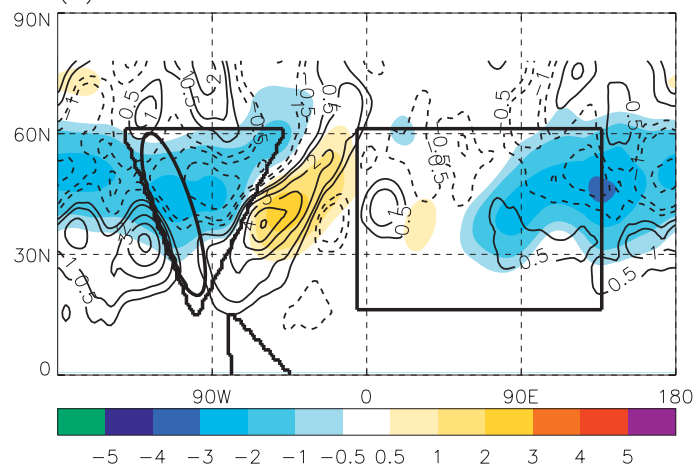

(b) Eady $850 \mathrm{hPa}$

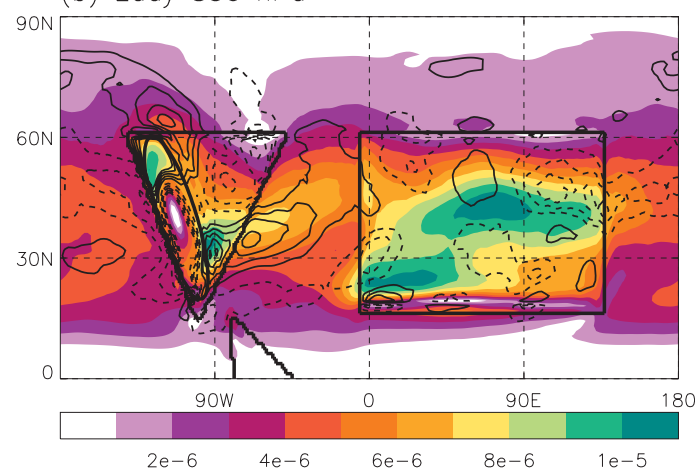

(d) Zonal wind

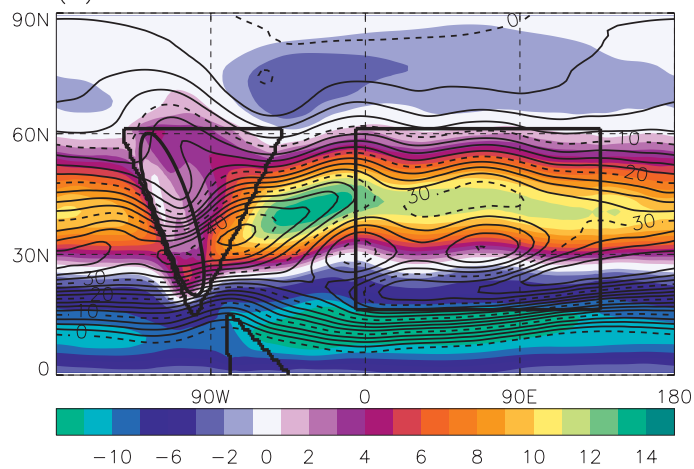

FIG. 14. As in Fig. 3, but for experiment $3 \mathrm{C}+\mathrm{R}$ with full fields and differences from flat $3 \mathrm{C}$ experiment.

baroclinicity extends eastward over the downstream ocean where, with reduced surface drag and increased moisture availability, it leads to a locally increased storm track.

- "Rocky Mountains"-like orography has perhaps the strongest effect on the flow of all the features discussed in this paper. An anticyclone is generated over the poleward portion of the mountain, where the flow predominantly goes "over" the mountain, whereas a cyclone is created on the equatorward section, where the flow is blocked (near the surface) or deflected "around" the mountain (above approximately 800 $\mathrm{hPa}$ ). The combined effect produces a strong southwest-northeast tilt to the jet and storm track on the downstream side.

The semirealistic framework allows these general findings to be applied more directly to realistic modeling situations. The land-sea contrast associated with the semirealistic Northern Hemisphere continents is shown to be capable of weakly localizing the storm track into the ocean basins. However, on its own, the southwestnortheast tilt of the eastern coastline of the North American continent is unable to reproduce the southwest-northeast tilt seen in the real North Atlantic storm track.
The subtropical edge of the Eurasian continent has been shown to significantly distort the downward branch of the Hadley cell, leading to a southward shift of the subtropical jet and a pronounced split-jet structure over Eurasia. Similar effects may also occur (but on a smaller scale) over the North American continent with the surface properties of the area around Mexico. The impact of subtropical (and tropical) landmasses on the Northern Hemisphere storm tracks would therefore be an interesting area for further research.

The North American continent is ideal with regard to its shape and the characteristics of its major mountain range for the generation of the downstream North Atlantic storm track. The northwest-southeast orientation of the Rocky Mountains and their southward extension into the subtropics blocks and deflects the background flow more strongly than a simple north-south-oriented mountain confined to the extratropics, leading to a strong southwest-northeast tilt in the jet and storm track over the downstream Atlantic. This southwest-northeast orientation of the flow is extremely favorable to the storm track because it lies along an axis similar to the east coast of North America, which contributes to the near-surface baroclinicity where the cold continental air meets the warm ocean. Indeed, the deflection of the flow by the 
(a) Omega $700 \mathrm{hPa}$ and precipitation

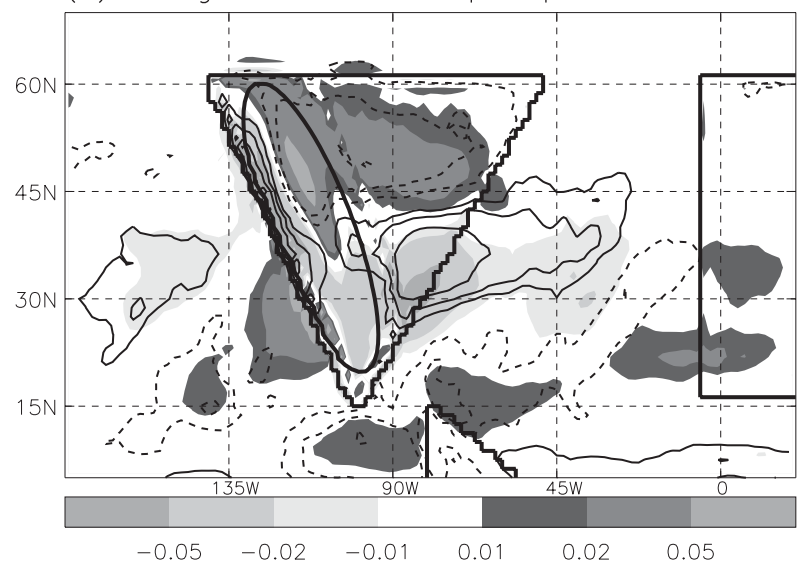

(b) Temp. and stream function anom. $700 \mathrm{hPa}$

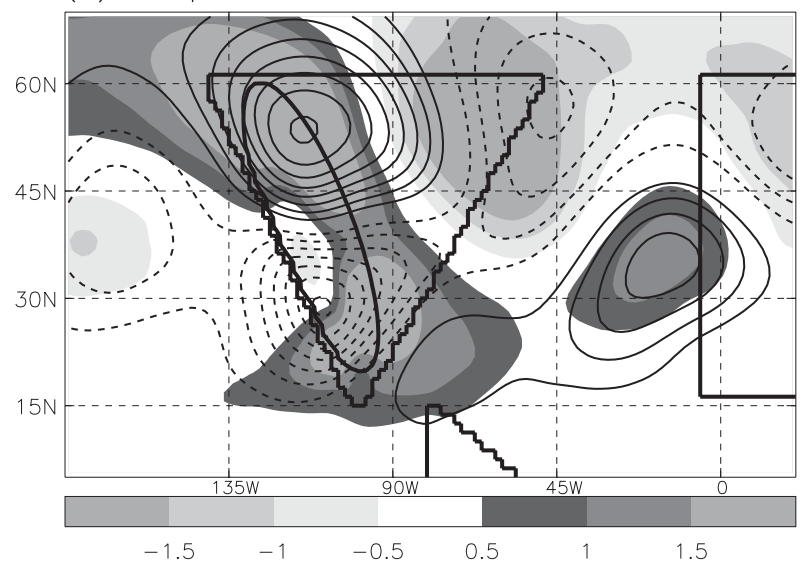

(c) Stream function $1000 \mathrm{hPa}$

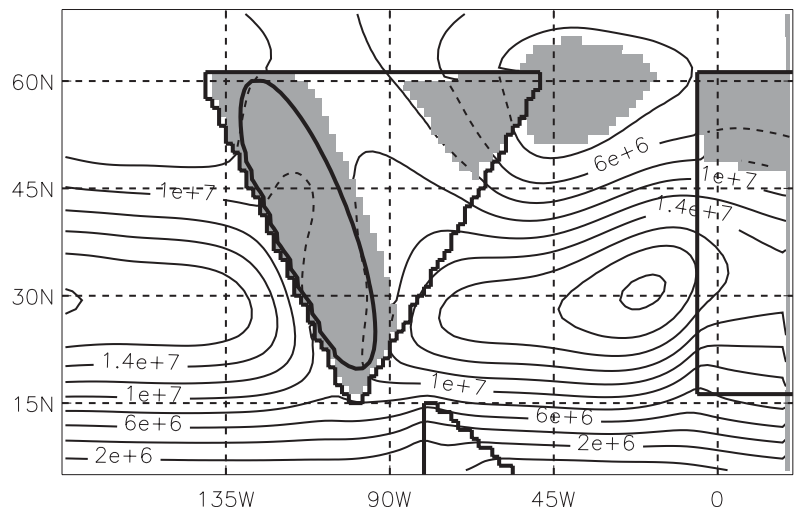

FIG. 15. The impact of the "Rocky Mountains"showing full fields and differences between $3 \mathrm{C}+\mathrm{R}$ and $3 \mathrm{C}$ (i.e., $3 \mathrm{C}+\mathrm{R}-3 \mathrm{C}$ ). (a) Differences in $\omega$ at $700 \mathrm{hPa}$ (shading, negative upward, $\mathrm{Pa} \mathrm{s}^{-1}$ ) and precipitation (contours at $0.5,1,2,4 \mathrm{~mm} \mathrm{day}^{-1}$, dashed for negative). (b) Differences in temperature at $700 \mathrm{hPa}$ (shading, K) and zonally asymmetric component of streamfunction at $700 \mathrm{hPa}$ (contours, $\mathrm{CI}=1 \times 10^{6} \mathrm{~m}^{2} \mathrm{~s}^{-2}$, dashed for negative). (c) Full field streamfunction at $1000 \mathrm{hPa}$ (contours, $\mathrm{CI}=2 \times 10^{6} \mathrm{~m}^{2} \mathrm{~s}^{-2}$ ); areas where the surface pressure is below $1000 \mathrm{hPa}$ are shaded. northern half of the mountain acts to deepen and extend the cold pool of air in the northeast corner of the continent, further enhancing the baroclinicity near the coastline. The land-sea contrast associated with the North American continent therefore plays a greater role in shaping the storm track and the large-scale flow pattern when the orography is included than when it is absent.

The results presented here therefore reinforce the importance of the Rocky Mountains in generating stationary waves that enhance the temperature difference between the eastern and western coasts of the North Atlantic, as discussed in Seager et al. (2002). Furthermore, the integrations described here use perpetual equinox solar conditions. The combined orography and land-sea contrast effect would be expected to be even stronger in winter (with its stronger westerly flow and greater land-sea temperature contrasts).

The region of downstream storm activity associated with the combined forcing by the Rocky Mountains and the North American continent lies very close to the Gulf Stream region in the real North Atlantic. The Gulf Stream could then be expected to further promote storm growth through the tighter SST gradients associated with it. Indeed, as Hoskins and Valdes (1990) noted, the surface wind stress produced by the storm track plays an important role in driving this current. The impact of the Gulf Stream and the North Atlantic drift will be examined in a subsequent study, based on research described in Brayshaw (2006).

Acknowledgments. The authors thank R. Seager and an anonymous reviewer for their thorough and thoughtful reviews that have helped to clarify and extend some key areas of the paper. This work was supported by the NERC Rapid Climate Change Programme, project reference NER/T/S/2002/00441.

\section{APPENDIX}

\section{Storm Track Diagnostics}

The storm tracks are analyzed using standard Eulerian (variance and covariance map) techniques (e.g., plotting maps of $\overline{v^{\prime} T^{\prime}}$ on the $850-\mathrm{hPa}$ surface). Such maps are calculated after the application of a 2-6-day Lanczos bandpass filter (Duchon 1979) on the raw data components (which are recorded at 6-h intervals). The filter has a total width of 30 days and isolates the 2-6-day window very well. The results are not sensitive to moderate variations in filter width.

The significance of the differences in the storm tracks is tested directly by using the nonparametric WilcoxonMann-Whitney (WMW) method (see, e.g., Wilks 1995). 
The storm track data were resampled at 5-day intervals to remove the serial correlation of the data (the autocorrelation of the storm track variables was found to be almost zero after this interval).

A "passive" storm track measure, the variance of bandpass-filtered geopotential height at $850 \mathrm{hPa}$, is used to describe the location and general strength of the storm track. Covariance maps of $\overline{v^{\prime} T^{\prime}}$ and $\overline{u^{\prime} v^{\prime}}$ provide a good insight into the eddy feedbacks on the mean flow when they are combined to produce diagnostics such as the $\mathbf{E}$ vector (Hoskins et al. 1983):

$$
\begin{aligned}
\mathbf{E}_{H} & =\left(\overline{\mathbf{v}^{\prime 2}-\mathbf{u}^{\prime 2}},-\overline{\mathbf{u}^{\prime} \mathbf{v}^{\prime}}\right), \\
E_{p} & =f \frac{\overline{\boldsymbol{v}^{\prime} \theta^{\prime}}}{\Theta_{p}} .
\end{aligned}
$$

Following the discussion in Brayshaw et al. (2008), a simple situation is considered in which the divergence of $\mathbf{E}_{H}$ in the upper troposphere is associated with a layer of pressure depth $\Delta p_{1}$. The modified meridional ageostrophic flow balancing this is assumed to return in a lower layer of depth $\Delta p_{2}$ where its torque is balanced by a linear drag $(\lambda)$ on the surface flow. This suggests that the strength of this surface flow is on the order of

$$
u_{H}=\frac{1}{\lambda} \frac{\Delta p_{1}}{\Delta p_{2}} \nabla_{H} \cdot \mathbf{E}_{H} .
$$

Similarly, consider a simple situation in which $E_{p}$ has a lower tropospheric maximum, decreasing to zero at the surface, where its heating and cooling are balanced by a meridional circulation and its surface torque is again balanced by a linear drag on the surface flow. This suggests that the strength of this surface flow is on the order of

$$
u_{p}=\frac{1}{\lambda} \frac{E_{p}}{\Delta p_{2}} .
$$

Here $E_{p}$ is a characteristic lower tropospheric value. The assumption that $E_{p}$ decreases to zero at the surface implies that Eq. (A4) is likely to be an overestimate.

In a zonal average, the surface winds associated with the transient eddies are driven by the vertical integral of $\mathbf{E}_{H}$. The meridional circulation that balances this upper tropospheric westerly driving by the eddies must also be consistent with balancing the heating and cooling associated with both $E_{p}$ and diabatic processes. Thus, the two estimates should be consistent in the zonal average in the absence of diabatic heating. However, for a longitudinally dependent setup they can each provide somewhat independent estimates of the local surface flow that would be in balance with the local eddy driving and can be compared with the actual surface flow. At the most basic level, Eqs. (A3) and (A4) can be considered to be just scalings of $\boldsymbol{\nabla} \cdot \mathbf{E}_{H}$ and $E_{p}$ that allow them to be plotted in similar units.

As in Brayshaw et al. (2008), we use the 250-hPa level for $\mathbf{E}_{H}$ and the 850-hPa level for $E_{p}$, and $\lambda$ corresponds to damping time scales $\left(\lambda^{-1}\right)$ of 0.7 and 0.35 days over ocean and land, respectively. Here the pressure depths $\Delta p_{1}$ and $\Delta p_{2}$ are taken as 450 and $150 \mathrm{hPa}$, respectively. The former is twice that used in Brayshaw et al. (2008) because this has been found to be a better representation of the upper tropospheric structure. A weak smoothing is applied before plotting to improve visibility. It should also be noted that the application of the 2-6-day bandpass filter (described above) approximately halves the magnitude of the E-vector components when compared to their total (unfiltered) values.

\section{REFERENCES}

Brankovic, C., F. Molteni, and P. Viterbo, 2006: GCM sensitivity experiments with locally modified land surface properties over tropical South America. Climate Dyn., 26, 729-749.

Brayshaw, D. J., 2006: Large scale forcing of the North Atlantic storm track. Ph.D. thesis, University of Reading, 213 pp.

- B. Boskins, and M. Blackburn, 2008: The storm track response to idealized SST perturbations in an aquaplanet GCM. J. Atmos. Sci., 65, 2842-2860.

Broccoli, A. J., and S. Manabe, 1992: The effects of orography on midlatitude Northern Hemisphere dry climates. J. Climate, 5, 1181-1201.

Cash, B. A., P. A. Kushner, and G. K. Vallis, 2005: Zonal asymmetries, teleconnections, and annular patterns in a GCM. J. Atmos. Sci., 62, 207-219.

Chang, E. K. M., and I. Orlanski, 1993: On the dynamics of a storm track. J. Atmos. Sci., 50, 999-1015.

Chen, S.-C., and K. E. Trenberth, 1988: Orographically forced planetary waves in the Northern Hemisphere winter: Steady state model with wave-coupled lower boundary formulation. J. Atmos. Sci., 45, 657-680.

Cook, K. H., 2003: Role of continents in driving the Hadley cells. J. Atmos. Sci., 60, 957-976.

— orography in a general circulation model and a linear model. J. Atmos. Sci., 49, 525-539.

Cornforth, R. J., B. J. Hoskins, and C. D. Thorncroft, 2009: The impact of moist processes on the African easterly jet-African easterly wave system. Quart. J. Roy. Meteor. Soc., 135, 894-913.

Duchon, C. E., 1979: Lanczos filtering in one and two dimensions. J. Appl. Meteor., 18, 1016-1022.

Frisius, T., F. Lunkeit, K. Fraedrich, and I. N. James, 1998: Stormtrack organization and variability in a simplified atmospheric global circulation model. Quart. J. Roy. Meteor. Soc., 124, 1019-1043.

Gill, A. E., 1980: Some simple solutions for heat-induced tropical circulation. Quart. J. Roy. Meteor. Soc., 106, 447-462.

Greeves, C. Z., V. D. Pope, R. A. Stratton, and G. M. Martin, 2007: Representation of Northern Hemisphere winter storm tracks in climate models. Climate Dyn., 28, 683-702. 
Held, I. M., M. Ting, and H. Wang, 2002: Northern winter stationary waves: Theory and modeling. J. Climate, 15, 2125-2144.

Hendon, H. H., 1986: The time-mean flow and variability in a nonlinear model of the atmosphere with tropical diabatic forcing. J. Atmos. Sci., 43, 72-88.

Hoskins, B. J., and D. J. Karoly, 1981: The steady linear response of a spherical atmosphere to thermal and orographic forcing. J. Atmos. Sci., 38, 1179-1196.

— J. Atmos. Sci., 47, 1854-1864.

- I. N. James, and G. H. White, 1983: The shape, propagation, and mean-flow interaction of large-scale weather systems. J. Atmos. Sci., 40, 1595-1612.

Inatsu, M., H. Mukougawa, and S.-P. Xie, 2000: Formation of subtropical westerly jet core in an idealized GCM without mountains. Geophys. Res. Lett., 27, 529-532.

,-- , and $\longrightarrow, 2002$ : Stationary eddy response to surface boundary forcing: Idealized GCM experiments. J. Atmos. Sci., 59, 1898-1915.

,-- , and -2003 : Atmospheric response to zonal variations in midlatitude SST: Transient and stationary eddies and their feedback. J. Climate, 16, 3314-3329.

Jin, F.-F., and B. J. Hoskins, 1995: The direct response to tropical heating in a baroclinic atmosphere. J. Atmos. Sci., 52, 307-319.

Kushnir, Y., and I. M. Held, 1996: Equilibrium atmospheric response to North Atlantic SST anomalies. J. Climate, 9, $1208-1220$.

Manabe, S., and A. J. Broccoli, 1990: Mountains and arid climates of middle latitudes. Science, 247, 192-195.

Nakamura, H., T. Sampe, Y. Tanimoto, and A. Shimpo, 2004: Observed associations among storm tracks, jet streams, and midlatitude oceanic fronts. Earth's Climate: The Ocean-Atmosphere Interaction, Geophys. Monogr., Vol. 147, Amer. Geophys. Union, 329-345.

,,-- A. Goto, W. Ohfuchi, and S.-P. Xie, 2008: On the importance of mid-latitude oceanic frontal zones for the mean state and dominant variability in the tropospheric circulation. Geophys. Res. Lett., 35, L15709, doi:10.1029/2008GL034010.

Neale, R. B., and B. J. Hoskins, 2000a: A standard test for AGCMs including their physical parameterizations. I: The proposal. Atmos. Sci. Lett., 1, 101-107.

— and - 2000b: A standard test for AGCMs including their physical parameterizations. II: Results for Met Office model. Atmos. Sci. Lett., 1, 108-114.

Nigam, S., I. M. Held, and S. W. Lyons, 1986: Linear simulation of the stationary eddies in a general circulation model. Part I: The no-mountain model. J. Atmos. Sci., 43, 2944-2961.

Palmer, T. N., and Z. Sun, 1985: A modelling and observational study of the relationship between sea surface temperature in the northwest Atlantic and the atmopsheric general circulation. Quart. J. Roy. Meteor. Soc., 111, 947-975.

Peng, S., and J. S. Whitaker, 1999: Mechanisms determining the atmospheric response to midlatitude SST anomalies. J. Climate, 12, 1393-1408.
, L. A. Mysak, H. Ritchie, J. Derome, and B. Dugas, 1995: The differences between early and midwinter atmospheric responses to sea surface temperature anomalies in the Northwest Atlantic. J. Climate, 8, 137-157.

_ W. A. Robinson, and M. P. Hoerling, 1997: The modeled atmospheric response to midlatitude SST anomalies and its dependence on background circulation states. J. Climate, 10, 971-987.

Pope, V. D., and R. A. Stratton, 2002: The processes governing horizontal resolution sensitivity in a climate model. Climate Dyn., 19, 211-216.

_ M. L. Gallani, R. R. Rowntree, and R. A. Stratton, 2000: The impact of new physical parameterizations in the Hadley Centre climate model: HadAM3. Climate Dyn., 16, 123-146.

Ringler, T. D., and K. H. Cook, 1997: Factors controlling nonlinearity in mechanically forced stationary waves over orography. J. Atmos. Sci., 54, 2612-2629.

Robinson, W. A., 1996: Does eddy feedback sustain variability in the zonal index? J. Atmos. Sci., 53, 3556-3569.

Rodwell, M. J., and B. J. Hoskins, 1996: Monsoons and the dynamics of deserts. Quart. J. Roy. Meteor. Soc., 122, 1385-1404.

Sardeshmukh, P. D., and B. J. Hoskins, 1988: The generation of global rotational flow by steady idealized tropical divergence. J. Atmos. Sci., 45, 1228-1251.

Seager, R., D. S. Battisti, J. Yin, N. Gordon, N. Naik, A. C. Clement, and M. A. Cane, 2002: Is the Gulf Stream responsible for Europe's mild winters? Quart. J. Roy. Meteor. Soc., 128, 2563-2586.

Stratton, R. A., 2004: Report on aspects of variability in highresolution versions of HadAM3. Hadley Centre Tech. Note. 53, Met Office, $31 \mathrm{pp}$.

Thorncroft, C. D., and M. Blackburn, 1999: Maintenance of the African easterly jet. Quart. J. Roy. Meteor. Soc., 125, 763-786.

Ting, M., and I. M. Held, 1990: The stationary wave response to a tropical SST anomaly in and idealized GCM.J. Atmos. Sci., 47, 2546-2566.

Uppala, S. M., and Coauthors, 2005: The ERA-40 re-analysis. Quart. J. Roy. Meteor. Soc., 131, 2961-3012.

Valdes, P. J., and B. J. Hoskins, 1989: Linear stationary wave simulations of the time-mean climatological flow. J. Atmos. Sci., 46, 2509-2527.

— , and — 1991: Nonlinear orographically forced planetary waves. J. Atmos. Sci., 48, 2089-2106.

Walter, K., U. Luksch, and K. Fraedrich, 2001: A response climatology of idealized midlatitude thermal forcing experiments with and without a storm track. J. Climate, 14, 467-484.

Wilks, D. S., 1995: Statistical Methods in the Atmospheric Sciences. Academic Press, 467 pp.

Wilson, C., B. Sinha, and R. G. Williams, 2009: The effect of ocean dynamics and orography on atmospheric storm tracks. J. Climate, 22, 3689-3702.

Zhang, H., K. McGuffie, and A. Henderson-Sellers, 1996: Impacts of tropical deforestation. Part II: The role of large-scale dynamics. J. Climate, 9, 2498-2521. 